\title{
El resurgimiento de la energía minihidráulica en España y su situación actual ${ }^{1}$
}

\author{
Cayetano Espejo Marín², Ramón García Marín³ \\ y Ana Eulalia Aparicio Guerrero ${ }^{4}$
}

\begin{abstract}
RESUMEN
Las centrales minihidráulicas han sido una fuente de energía pionera para la producción de electricidad desde finales del siglo XIX. La crisis del petróleo en los años setenta del siglo XX puso de relieve la necesidad de apostar por las energías renovables, por su carácter autóctono, porque reducían la dependencia del exterior y por su menor impacto ambiental. Este artículo analiza la evolución de la energía minihidráulica en España desde mediados del siglo XX a la actualidad. El análisis del marco legal que afecta a esta tecnología energética y la evolución de la potencia instalada en las últimas décadas han permitido determinar su resurgimiento y desarrollo, así como conocer las limitaciones actuales. Desde la aprobación de la Ley de Sector Eléctrico (1997) se ha incrementado en un $90 \%$ el número de minicentrales, un $52 \%$ la potencia instalada y un $72 \%$ la energía generada. Se ha dado un balance muy positivo, aunque en la actualidad el sector está estancado como consecuencia de las dificultades existentes para la nueva implantación de estas instalaciones, y en especial por las directrices de la nueva Política Energética para las renovables.
\end{abstract}

Palabras clave: Energía, Minihidráulica, Política Energética, Normativa, Distribución territorial.

\begin{abstract}
Small hydro power plants have been a pioneering energy source for electricity production since the late nineteenth century. The oil crisis of the 1970s highlighted the need to focus on renewable energies, as these reduce dependence on other energy producing countries and reducing their environmental impact. This article analyzes the evolution of minihydraulic energy in Spain from the mid - 20th century to the present. The analysis of the legal framework that affects this energy technology and the evolution of the installed power in the last decades have allowed to determine its resurgence and development, as well as to know the current limitations. Since the approval of the Electricity Sector Law (1997), the number of Small hydro power plants has increased by $90 \%, 52 \%$ of installed capacity and $72 \%$ of the energy generated. The balance of recent years is very positive, although at present the sector is stalled as a result of the difficulties existing for the new implementation of these facilities, and in particular by the guidelines of the new Energy Policy for renewables.
\end{abstract}

Keywords: Energy, Small Hydropower, Energy Policy, Regulations, Territorial distribution.

Artículo recibido el 23 de septiembre de 2016, aceptado el 24 de abril de 2017 y corregido el 12 de junio de 2017. 
Las centrales minihidráulicas son instalaciones que utilizan la energía mecánica de un curso de agua para la producción de energía eléctrica. En España, como en otros países que cuentan con recursos hídricos y una topografía favorable, han sido una fuente de energía pionera para la producción de electricidad desde finales del siglo XIX. La aparición de la corriente alterna amplió la zona que podían abastecer y por tanto su papel geoestratégico. Entre los años cincuenta y sesenta del siglo XX, el incremento de la demanda de electricidad para abastecimiento y alumbrado de las ciudades, junto con el de las industrias, llevó a que se construyeran grandes centrales hidroeléctricas y térmicas capaces de abastecer estas nuevas necesidades energéticas, lo que provocó el cierre de centenares de minicentrales hidroeléctricas por falta de rentabilidad frente a otras grandes instalaciones. Tras la crisis del petróleo de los años setenta y la situación de emergencia que se generó, los Gobiernos sucesivos comenzaron a pensar en las energías renovables, por su carácter autóctono y con la finalidad de reducir la dependencia energética del exterior, a la vez que por su menor impacto ambiental.

Este artículo tiene como objetivo analizar la evolución de la energía minihidráulica en España desde los años ochenta del siglo pasado, y explicar las razones que justifican su resurgimiento, desarrollo y situación actual.

A la energía minihidráulica en España se han dedicado varios estudios desde comienzos de los años noventa del siglo pasado. Sánchez (1994) trata la situación de las minicentrales en España en esos momentos, los aspectos técnicos de estas instalaciones, los elementos que las constituyen, los modernos equipos de automatización, y las condiciones técnicas para los productores de energía eléctrica; mientras que Domínguez (1994a) plantea la necesidad de un estudio hidrológico y de los aspectos ambientales a tener en cuenta previo a la construcción de una minicentral. Martínez (1995) considera que la evolución de esta tecnología energética ha sido muy positiva desde mediados de los años ochenta, debido a los Planes Energéticos comprendidos entre 1983 y 2000, el marco jurídico, los Programas Comunitarios de apoyo financiero y las tarifas eléctricas. Santos (2003) ha estudiado la utilización de la energía de un curso de agua en centrales de pequeña potencia: parámetros principales y esquemas, equipamiento principal, dispositivos de alimentación y descarga de pequeñas turbinas, y tendencias modernas en su diseño. En una línea aproximada Galán (2006) aborda sus fundamentos técnicos, grado de desarrollo, debilidades y fortalezas del sector, e impacto ambiental de esta tecnología. Castro (2006) analiza la situación en ese momento del sector, la tecnología y aplicaciones, los factores económicos, administrativos y medio ambientales, las ventajas de las minicentrales hidroeléctrica y sus perspectivas futuras. En 2006 la European Small Hydropower Association publica la versión actualizada del "Manual de pequeña hidráulica", editado por primera vez en 1998.

Sobre la evolución de la energía hidráulica en España, Espejo y García (2010) establecen cinco etapas en su desarrollo desde 1900. En la quinta (1990-2008) analizan las consecuencias sobre la minihidráulica de las políticas de fomento de las energías renovables: Planes Energéticos Nacionales y Ley del Sector Eléctrico de 1997. Otros estudios dedicados a este sector han tenido una componente geográfica a distintas escalas, cubriendo los siguientes territorios: Comarca de Béjar (Domínguez, 1992), Sierra de Gredos (Domínguez, 1994b), Castilla y León (Domínguez, 1996, 2000), Navarra (Garrués, 1997; Galán, 2004), Galicia (De Torres 
et al., 1988; Soto, 1996), cuencas de los ríos Tajo y Guadiana (Rojas, 2001), y Sierra Mágina (López et al., 2006).

El desarrollo de las energías renovables en España desde los años noventa del siglo pasado ha dado lugar a la aparición de nuevos paisajes energéticos. A ellos se han dedicado artículos que analizan tanto la integración paisajística de estas energías (Prados et al., 2012), como los paisajes emergentes generados (Frolova et al., 2014). Sobre paisaje y energía hidráulica se han analizado casos a nivel nacional y regional (Frolova, 2010; Frolova et al., 2015).

Durante los últimos años, la reforma estructural del sector eléctrico en España ha provocado cambios significativos en el régimen económico de las energías renovables, Martín y Sánchez (2014) dan buena cuenta de ello en una aportación titulada "La cascada legislativa que ahoga las energías renovables".

A escala global, y de acuerdo con World Small Hydropower Development Report (2016), la energía hidroeléctrica es la forma de energía renovable más utilizada, con más de 1,2 teravatios (TW) de capacidad instalada. Sin embargo, la potencia instalada a nivel mundial de las pequeñas hidroeléctricas (hasta $10 \mathrm{MW}$ ) se estima en 78 gigavatios (GW) en 2016. Las minicentrales representan aproximadamente el 1,9\% de la capacidad total de energía del planeta, el $7 \%$ de la capacidad total de energía renovable y el $6,5 \%$ del total de la capacidad hidroeléctrica (incluido el almacenamiento por bombeo). China ocupa el primer puesto con el $51 \%$ de la potencia hidroeléctrica instalada total y el $29 \%$ del potencial total mundial. Este país acumula más de cuatro veces la capacidad instalada conjunta de Italia, Japón, Noruega y los Estados Unidos de América. Esos 5 países representan el 67\% de la capacidad instalada total del mundo. Según este informe, la energía minihidráulica aún ofrece grandes posibilidades de desarrollo. En las Américas: Estados Unidos ha desarrollado gran parte de su potencial, alcanzando el $57 \%$ de su capacidad previsible; Brasil tiene mucho de su potencial sin desarrollar, alcanzando sólo el 30\% en 2016; mientras que las dos regiones más pequeñas -el Caribe y Centroamérica- aún no han hecho evaluaciones concluyentes para determinar sus potenciales reales. En este continente, la mayoría de las minihidráulicas se concentran en Centroamérica y América del Sur. Europa, por otra parte, tiene la mayor tasa de desarrollo, con casi el $48 \%$ del potencial total ya instalado, y Europa Occidental posee el $85 \%$ de su potencial ya desarrollado. Japón y la India también tienen este sector menos explotado, alcanzando sólo el $35 \%$ y el $18 \%$ respectivamente. Debido en gran parte al predominio de China, anteriormente comentado, Asia es el continente con mayor capacidad instalada (50.729 MW), lo que representa aproximadamente el $65 \%$ de la participación total. Por su parte, Oceanía tiene la participación más baja (1\%). África aún tiene un gran potencial de mejora, pues solamente ha desarrollado un 5\% su capacidad real estimada. África del Este, en particular, es la subregión que tiene el mayor potencial de progreso, pero también es la menos desarrollada en este sector por ahora.

En la Unión Europea la presencia de centrales minihidráulicas se concentra en un reducido número de países (Cuadro № 1). España tiene un papel relevante, ya que ocupa el tercer puesto en potencia instalada (13,96\% del total), el cuarto en producción de electricidad (11,09\%), el décimo en el número de empleos $(3,47 \%)$ debido al proceso de automatización implantado en la mayoría de minicentrales, y el quinto lugar en volumen de negocio $(7,11 \%)$. 


\section{Cuadro No 1}

Datos básicos de la energía minihidráulica en los países de la Unión Europea, 2015

\begin{tabular}{|c|c|c|c|c|}
\hline & $\begin{array}{c}\text { Potencia } \\
\text { instalada MW }\end{array}$ & $\begin{array}{l}\text { Producción } \\
\text { eléctrica GWh }\end{array}$ & $\begin{array}{l}\text { Número de } \\
\text { empleos }\end{array}$ & $\begin{array}{l}\text { Volumen de } \\
\text { negocio. M€ }\end{array}$ \\
\hline Italia & 3.208 & 10.864 & 5.000 & 1.000 \\
\hline Francia & 2.065 & 5.735 & 3.900 & 450 \\
\hline España & 1.953 & 5.015 & 1.600 & 380 \\
\hline Alemania & 1.327 & 4.672 & 6.700 & 320 \\
\hline Austria & 1.280 & 5.434 & 5.850 & 1.635 \\
\hline Suecia & 961 & 4.087 & 4.000 & 250 \\
\hline Rumanía & 518 & 1.261 & 2.600 & 30 \\
\hline Portugal & 394 & 795 & 2.000 & 40 \\
\hline Reino Unido & 350 & 1.289 & 5.500 & 850 \\
\hline República Checa & 335 & 1.002 & 1.750 & 70 \\
\hline Finlandia & 306 & 1.288 & 400 & 75 \\
\hline Bulgaria & 301 & 1.062 & 400 & 20 \\
\hline Polonia & 279 & 822 & 1.450 & 100 \\
\hline Grecia & 223 & 707 & 2.500 & 20 \\
\hline Eslovenia & 157 & 327 & 750 & 10 \\
\hline Eslovaquia & 75 & 117 & 400 & 20 \\
\hline Bélgica & 66 & 186 & 350 & 15 \\
\hline Irlanda & 41 & 123 & 200 & $\leq 5$ \\
\hline Croacia & 36 & 101 & 250 & 25 \\
\hline Luxemburgo & 34 & 99 & 150 & $\leq 5$ \\
\hline Letonia & 29 & 74 & 150 & $\leq 5$ \\
\hline Lituania & 27 & 69 & $\leq 50$ & $\leq 5$ \\
\hline Hungría & 16 & 59 & 100 & $\leq 5$ \\
\hline Dinamarca & 7 & 18 & $\leq 50$ & $\leq 5$ \\
\hline Estonia & 6 & 27 & $\leq 50$ & $\leq 5$ \\
\hline Chipre & 0 & 0 & 0 & 0 \\
\hline Malta & 0 & 0 & 0 & 0 \\
\hline Holanda & 0 & 0 & 0 & 0 \\
\hline
\end{tabular}

Fuente: EurObserv'ER. The state of renewable energies in Europe, 2016.

Las preguntas que nos planteamos para el desarrollo de este artículo son las siguientes: ¿Cuáles son las causas de la recuperación de la energía minihidráulica en España? ¿Qué impacto ha tenido en el sector la Política de Fomento de las Energías renovables en nuestro país? ¿Qué factores limitan en la actualidad su desarrollo? Para conocer la evolución de la potencia instalada desde los años sesenta hasta finales de los ochenta contamos con los datos publicados en estudios sobre 
este sector; para la década de los noventa las publicaciones del Instituto para la Diversificación y Ahorro de la Energía ofrecen datos relevantes; y tras la promulgación en diciembre de 1997 de la Ley del Sector Eléctrico, desde 1998 la Comisión Nacional de Energía ofrece información detallada (potencia y producción) por Comunidades Autónomas. Las dificultades que afectan al sector, tanto en lo referente a las barreras tradicionales, como a sus problemas recientes, se han recopilado con detalle en los documentos de los Planes de Fomento de las Energías Renovables. También hay que destacar el papel de la prensa regional y nacional como fuente de información, por las abundantes noticias sobre la reacción del sector por la vía judicial ante las recientes reformas energéticas del Gobierno de España, y sus consecuencias manifiestas en la reducción de los ingresos para las empresas propietarias de las minicentrales.

El artículo se desarrolla con los siguientes apartados: definición de pequeño aprovechamiento hidráulico, tipos de centrales (de agua fluyente, de pie de presa y en canal de riego), unas breves notas sobre los orígenes y evolución de la minihidráulica hasta los años ochenta. A continuación se analiza el papel de esta energía en la planificación energética, primero en la general y desde finales de los años noventa y hasta la actualidad en los Planes de Fomento de las Energías Renovables. También se estudia la normativa legislativa que ha permitido su desarrollo. Tras la presentación de planes, leyes y normas se trata la evolución de la potencia instalada y la distribución geográfica de las centrales, la capacidad productiva y la producción eléctrica. Igualmente, se alude a la incertidumbre que padece en la actualidad este sector, tanto por las dificultades tradicionales derivadas del uso de un recurso básico como el agua, como por las consecuencias de las últimas medidas adoptadas por el Gobierno de España en materia de energías renovables, y que han supuesto una reseñable reducción de los ingresos por la venta de la electricidad que producen.

\section{Definición de pequeño aprovechamiento hidroeléctrico}

Según la European Small Hydropower Association (2006), no existe consenso entre los estados miembros de la Unión Europea para definir la minihidráulica. Algunos países como Portugal, España, Irlanda, Grecia y Bélgica consideran "pequeñas" todas las centrales cuya potencia instalada no supera los $10 \mathrm{MW}$, aunque desde el punto de vista tarifario las centrales entre $10 \mathrm{MW}$ y 50 MW tienen ciertas ventajas. En Italia el límite está situado en los 3 MW (la electricidad procedente de centrales de mayor tamaño tiene un precio sensiblemente inferior). En Francia, el límite se ha establecido recientemente en $12 \mathrm{MW}$, no como especificación de "pequeño aprovechamiento", sino como potencia máxima por debajo de la cual la red tiene obligación de adquirir la electricidad generada por las mismas. En el Reino Unido no existe limite oficial, pero parece prevalecer el criterio de los $10 \mathrm{MW}$.

En España, la Ley 82/1980 sobre Conservación de Energía, establecía que solo podían acogerse a su régimen de beneficios las instalaciones con una potencia máxima de $5 \mathrm{MW}$. Con posterioridad, el Real Decreto 2366/1994 sobre producción de energía eléctrica por instalaciones hidráulicas, de cogeneración y otras abastecidas por recursos o fuentes renovables, incluidas en el régimen especial, indicaba que se podían beneficiar de su régimen económico las centrales hidroeléctricas cuya potencia no fuera superior a los $10 \mathrm{MW}$. Cuatro años más tarde, el Real Decreto 2818/1998 sobre producción de energía eléctrica por instalaciones abastecidas por recursos o fuentes de energía renovables, residuos y cogeneración, advertía que se podrían acoger al régi- 
men especial las instalaciones con potencia instalada inferior o igual a $50 \mathrm{MW}$. En este artículo consideraremos minicentrales hidroeléctricas las que cuentan con una potencia de hasta $10 \mathrm{MW}$.

\section{Tipos de minicentrales hidroeléctricas}

Las centrales hidroeléctricas, y dentro de ellas las minicentrales, están muy condicionadas por las peculiaridades y características del lugar donde vayan a ser ubicadas. Para la puesta en marcha de una instalación de este tipo hay que tener en cuenta que la topografía del terreno influirá tanto en la obra civil como en la selección de la maquinaria. Según el emplazamiento se clasifican en:

- Centrales de agua fluyente, que captan una parte del caudal del río y lo trasladan hacia la central, y una vez utilizado, se devuelve al río; la característica común a todas ellas es que dependen directamente de la hidrología, ya que no tienen capacidad de regulación del caudal turbinado y éste es muy variable.

- Centrales de pie de presa, que se sitúan debajo de los embalses destinados a usos hidroeléctricos o a otros usos, aprovechando el desnivel creado por la propia presa. La característica principal de este tipo de instalaciones es que cuentan con la capacidad de regulación de los caudales de salida, que serán turbinados en los momentos que se precise. Esta capacidad de controlar el volumen de producción se emplea en general para proporcionar energía durante las horas punta de consumo.

- Centrales en canal de riego o de abastecimiento. Se distinguen dos tipos: aquellas que utilizan el desnivel existente en el propio canal, mediante la instalación de una tubería forzada paralela a la vía rápida del canal de riego que conduce el agua hasta la central, devolviéndola posteriormente a su curso normal en canal; y aquellas que aprovechan el desnivel existente entre el canal y el curso de un río cercano. La central en este caso se instala cercana al río y se turbinan las aguas excedentes en el canal (Castro, 2006).

\section{Notas sobre sus antecedentes históricos}

Los primeros aprovechamientos hidroeléctricos de los ríos fueron pequeñas centrales destinadas al alumbrado, muy próximas al lugar de consumo. En 1888 se puso en funcionamiento el alumbrado eléctrico de Pamplona con la energía, en corriente continua, generada en la central del Molino de Santa Engracia, de 2,2 metros de salto y $5.000 \mathrm{l} / \mathrm{seg}$. de caudal con dos turbinas de 150 CV (110 kW) de potencia total (Galán, 2004).

La extensión de la electricidad en España tuvo lugar por la construcción de numerosas minicentrales hidroeléctricas, instalaciones que no superaban los $5.000 \mathrm{~kW}$. En el primer tercio del siglo XX gran número de minicentrales abastecían de energía a las poblaciones cercanas, ya que entonces no era viable el transporte de electricidad a grandes distancias. Estas instalaciones funcionaban en régimen de islas y frecuentemente con horario discontinuo (Domínguez, 1994a). Las centrales hidroeléctricas, que tenían la ventaja de unos costes de generación bajos ya que no 
consumían combustibles, sufrían en cambio la barrera de la distancia. Su forzoso emplazamiento a pie de un salto de agua les impedía suministrar a los centros urbanos, donde podían haber encontrado una mayor demanda. Gran parte de estas pequeñas centrales instaladas en el siglo XIX pertenecían a autoproductores (Urteaga, 2003).

El descubrimiento del transformador de corriente alterna posibilitó el transporte eléctrico a mayor distancia y obligó a crear grandes compañías hidroeléctricas capaces de generar un volumen energético muy superior al requerido en principio por la demanda urbana (Arroyo, 2012). En los años treinta se abordaron los proyectos a gran distancia de electricidad producida en plantas cada vez mayores (Domínguez, 1996). Durante estos años se realizan grandes obras hidráulicas que permiten la instalación de numerosas centrales, al tiempo que se consolidan las grandes empresas de producción y distribución de energía eléctrica. La política de apoyo al crecimiento de estas compañías, su influencia creciente en la fijación de tarifas de la electricidad y el reparto "de facto" del país en zonas de influencia, en la que actuaban en régimen de monopolio, determinaron el progresivo abandono del sector eléctrico por los pequeños productores. Estos vendieron sus instalaciones y derechos a los grandes del sector, que cerraron la mayoría de las minicentrales porque no encajaban en sus planes de producción y explotación, configurados sobre la base de grandes plantas productoras. La influencia de esta política sobre el parque de minicentrales se recoge en el Cuadro № 2, donde se ve que entre 1964 y 1982 se paralizaron más de un millar de centrales (Domínguez, 1994a). También influyó en el cierre de numerosas minicentrales el bajo precio del crudo, que fomentó la construcción de grandes centrales térmicas, más competitivas en aquel momento, frente a los costes excesivos de explotación de las minicentrales (Martínez, 1995).

Cuadro No 2

Evolución del parque de pequeñas centrales hidroeléctricas. 1964-1982

\begin{tabular}{|l|r|r|r|}
\hline Año & Número de Centrales & Potencia instalada MW & Producción anual GWh \\
\hline 1964 & 1.740 & 609 & 1.990 \\
\hline 1978 & 735 & 500 & 1.700 \\
\hline 1982 & 576 & 327 & 1.150 \\
\hline
\end{tabular}

Fuente: Martínez (1995) y Domínguez (1994a).

Se mantuvieron las centrales que eran rentables, normalmente las de mayor potencia, con las pequeñas mejoras que iba incorporando la evolución de la técnica, pero tenían necesariamente el carácter de complementarias de la energía garantizada por otros medios. A modo de ejemplo, la provincia de Navarra pasó de 232 minicentrales en 1945, con una potencia total de 60,8 MW, a 63 centrales en 1980, con una potencia total de 77 MW (Galán, 2004).

Durante la década de 1970, en muchos países desarrollados y en vías de desarrollo, debido a la crisis energética mundial, las centrales hidroeléctricas de pequeña potencia atrajeron nuevamente la atención por varias razones: el brusco incremento en el precio del petróleo, el alto índice de utilización del potencial hidroenergético de los medios y grandes cursos de agua, la tendencia al uso múltiple de los recursos hidráulicos y el perfeccionamiento de las soluciones de proyecto y de 
la tecnología de construcción y explotación de las centrales de pequeña potencia, así como el incremento de su efectividad económica (Santos, 2003). Fueron necesarios el desencadenamiento de la crisis energética de los años setenta y la promulgación de la Ley 82/1980 de Conservación de la Energía, así como el desarrollo de medidas de fomento de la producción en minicentrales, para que se considerase la reapertura y rehabilitación de muchas centrales clausuradas. Se abordaron las primeras tareas de prospección del potencial minihidráulico de cada una de las cuencas hidrográficas (Domínguez, 1994a). En 1980 se creó la Comisión de Estudio de Pequeñas Centrales, compuesta por representantes de la Administración y de las empresas que integraban la patronal eléctrica UNESA. Su primer trabajo fue elaborar un estudio para conocer el potencial hidroeléctrico aprovechable a base de minicentrales existentes en la Península. El resultado fue un informe realizado por la Comisaría de Energía, la Dirección General de Obras Hidráulicas y UNESA. Titulado "Estudio sobre el aprovechamiento del potencial hidroeléctrico con centrales de pequeña potencia", analizaba el potencial teórico de los ríos o tramos de río que tienen interés desde el punto de vista energético (Pérez, 2002). En el Cuadro No 3 se representa la irregularidad de la distribución del potencial hidroeléctrico, tanto el bruto como el técnicamente desarrollable, en las distintas cuencas. También puede apreciarse la importancia de las minicentrales, cuyo potencial es del orden del $10 \%$ de las grandes, lo cual justifica el interés de la Administración española para fomentar la recuperación de las construidas y abandonadas, y la construcción de nuevas y viables (Martínez, 1995).

Cuadro No 3

Distribución por cuencas hidrográficas del potencial hidroeléctrico en España GWh/año (1980)

\begin{tabular}{|c|c|c|c|c|c|c|}
\hline \multirow{2}{*}{$\begin{array}{l}\text { Cuenca } \\
\text { Hidrográfica }\end{array}$} & \multicolumn{3}{|c|}{$\begin{array}{l}\text { Potencial de } \\
\text { futura utilización }\end{array}$} & \multirow[b]{2}{*}{ Total } & \multirow{2}{*}{$\begin{array}{c}\text { Total } \\
\text { potencial } \\
\text { técnicamente } \\
\text { desarrollable }\end{array}$} & \multirow{2}{*}{$\begin{array}{l}\text { Potencial } \\
\text { fluvial } \\
\text { bruto }\end{array}$} \\
\hline & $\begin{array}{l}\text { Potencial } \\
\text { diferenciado }\end{array}$ & $\begin{array}{c}\text { Aprovechamientos } \\
\text { medianos y } \\
\text { grandes }\end{array}$ & $\begin{array}{c}\text { Aprov. } \\
\text { pequeños }\end{array}$ & & & \\
\hline Norte & 10.600 & 9.300 & 2.700 & 12.000 & 22.600 & 34.280 \\
\hline Duero & 6.700 & 4.200 & 600 & 4.800 & 11.500 & 29.400 \\
\hline Tajo & 3.900 & 4.200 & 600 & 4.800 & 8.700 & 16.540 \\
\hline Guadiana & 300 & 300 & & 300 & 600 & 3.830 \\
\hline Guadalquivir & 400 & 500 & 300 & 800 & 1.200 & 10.410 \\
\hline $\begin{array}{l}\text { Sur de } \\
\text { España }\end{array}$ & 200 & 100 & 300 & 400 & 600 & 2.740 \\
\hline Segura & 100 & 600 & 100 & 700 & 800 & 2.090 \\
\hline Júcar & 1.200 & 1000 & 400 & 1.400 & 2.600 & 7.490 \\
\hline Ebro & 7.600 & 7000 & 1.400 & 8.400 & 16.000 & 40.060 \\
\hline $\begin{array}{l}\text { Pirineo } \\
\text { Oriental }\end{array}$ & 600 & 100 & 300 & 400 & 1.000 & 3.520 \\
\hline $\begin{array}{l}\text { Total } \\
\text { cuencas }\end{array}$ & 31.600 & 27.300 & 6.700 & 34.000 & 65.600 & 150.360 \\
\hline
\end{tabular}

Fuente: Instituto para la Diversificación y Ahorro de la Energía. Plan de Fomento de las Energías Renovables. Domínguez (1994a). 


\section{La política energética en la minihidráulica}

Junto con la disponibilidad de los recursos hídricos necesarios para la instalación de centrales hidroeléctricas de reducido tamaño, las políticas energéticas desarrolladas en España desde comienzos de la década de los ochenta del siglo XX han impulsado su desarrollo en una doble vertiente: rehabilitación y construcción; $y$ a su vez las decisiones políticas más recientes han provocado un freno en el sector y un difícil futuro para muchas minicentrales. A continuación se presenta una síntesis de la minihidráulica en los Planes Energéticos Nacionales y en los dedicados al fomento de las Energías Renovables. Igualmente se relaciona el marco legislativo derivado de estos Planes.

\section{Los planes energéticos}

Después de la creación en 1980 de la Comisión de Estudio de Pequeñas Centrales y la realización del informe junto con la Comisaría de Energía, la Dirección General de Obras Hidráulicas y UNESA, queda de manifiesto que tras el aprovechamiento de los grandes saltos y caudales de agua de los ríos y corrientes más importantes, con grandes embalses en cabecera y sofisticados sistemas de regulación de la potencia, permanecen aún muchos pequeños saltos y embalses de poca capacidad, destinados a otros usos, que son susceptibles de ser aprovechados para la generación de energía eléctrica. Una de las posibles soluciones para la construcción de centrales de pequeña potencia es el aprovechamiento de los desniveles existentes en canales destinados a riego o abastecimiento de agua a ciudades o industrias (Rojas, 2001). Para aprovechar este potencial comienzan a diseñarse Planes Energéticos en los que cada vez tiene más importancia la energía minihidráulica (Cuadro No 4), cuya potencia instalada ha evolucionado favorablemente entre los años 1999 y 2004 (Cuadro No 5).

Cuadro No 4

Los Planes Energéticos

\begin{tabular}{|l|l|}
\hline Planes & \multicolumn{1}{|c|}{ Estrategias / Objetivos } \\
\hline $\begin{array}{l}\text { Plan Energético } \\
\text { Nacional 1983 }\end{array}$ & $\begin{array}{l}\text { Las energías renovables deberán jugar un papel cada vez más importante } \\
\text { en los balances energéticos del futuro. }\end{array}$ \\
\hline $\begin{array}{l}\text { Plan de Energías } \\
\text { Renovables 1986 }\end{array}$ & $\begin{array}{l}\text { Introducción de las energías renovables en general y de la energía } \\
\text { hidroeléctrica en particular. } \\
\text { Minihidráulica: se establece para 1988 un objetivo de incremento de } \\
\text { potencia de 200 MW }\end{array}$ \\
\hline $\begin{array}{l}\text { Plan de Energías } \\
\text { Renovables 1989- } \\
1995\end{array}$ & $\begin{array}{l}\text { Incremento en la utilización de estas energías en nuestro país. } \\
\text { Minihidráulica: instalación de 256 MW de potencia eléctrica. }\end{array}$ \\
\hline $\begin{array}{l}\text { Plan Energético } \\
\text { Nacional 1991- } \\
2000\end{array}$ & $\begin{array}{l}\text { Ampliación de los contenidos del Plan de Energías Renovables 1989. } \\
\text { Renotro programas entre los que se encuentra el Programa de Energías }\end{array}$ \\
\hline $\begin{array}{l}\text { Plan de Fomento } \\
\text { de las Energías } \\
\text { Renovables } \\
2000-2010\end{array}$ & $\begin{array}{l}\text { Las energías renovables deben cubrir, en su conjunto, al menos el 12\% del } \\
\text { consumo de energía primaria en el año 2010. } \\
\text { Minihidráulica: se plantea un aumento de la potencia y de la producción de } \\
\text { 720 MW y 2.232 GWh/año respectivamente. }\end{array}$ \\
\hline
\end{tabular}


Continuación Cuadro $N^{\circ} 4$

\begin{tabular}{|c|c|}
\hline Planes & Estrategias / Objetivos \\
\hline $\begin{array}{l}\text { Plan de Energías } \\
\text { Renovables 2005- } \\
2010\end{array}$ & $\begin{array}{l}\text { Sustituye al Plan de Fomento de Energías Renovables, cuyos resultados } \\
\text { fueron insuficientes. Sus objetivos, en la mayoría de los casos, difieren de } \\
\text { los objetivos del Plan de Fomento anterior. } \\
\text { Mantiene el compromiso de cubrir con fuentes renovables al menos el } 12 \% \\
\text { del consumo total de energía en } 2010 \text {, objetivo de las políticas de fomento } \\
\text { de las energías renovables en la Unión Europea desde la aprobación del } \\
\text { Libro Blanco en } 1997 \text {. } \\
\text { Incorpora los otros dos objetivos comunitarios indicativos para el año } 2010 \\
-29,4 \% \text { de generación eléctrica con renovables y } 5,75 \% \text { de biocarburantes } \\
\text { en transporte-. } \\
\text { Por Comunidades Autónomas, los objetivos más ambiciosos se fijan para } \\
\text { Castilla y León, seguida de lejos por Aragón y Cataluña, puesto que son } \\
\text { las Comunidades que cuentan con mayores recursos hidroeléctricos } \\
\text { pendientes de desarrollar. } \\
\text { Minihidráulica: incremento de potencia hidroeléctrica de } 450 \text { MW en el } \\
\text { periodo } 2005-2010 \text {, con lo que se lograría una potencia global de } 2.199 \\
\text { MW. } \\
\text { Se espera que uno de los mayores incrementos de potencia se produzca } \\
\text { en Galicia. }\end{array}$ \\
\hline $\begin{array}{l}\text { Plan de Energías } \\
\text { Renovables 2011- } \\
2020\end{array}$ & $\begin{array}{l}\text { Acorde con la Directiva 2009/28/CE del Parlamento Europeo y del Consejo, } \\
\text { de } 23 \text { de abril de 2009, relativa al fomento del uso de energía procedente } \\
\text { de fuentes renovables. Atiende a los mandatos del Real Decreto 661/2007, } \\
\text { por el que se regula la actividad de producción de energía eléctrica en } \\
\text { régimen especial y de la Ley } 2 / 2011 \text {, de } 4 \text { de marzo, de Economía Sostenible. }\end{array}$ \\
\hline
\end{tabular}

Fuente: Elaboración propia basado en Martínez (1995).

\section{Cuadro No 5}

Potencia instalada minihidráulica en el periodo de vigencia del Plan de Fomento de Energías Renovables 1999-2010 (MW)

\begin{tabular}{|l|r|r|r|r|r|r|r|}
\hline Hasta 1998 & \multicolumn{1}{|c|}{1999} & \multicolumn{1}{c|}{2000} & \multicolumn{1}{c|}{2001} & \multicolumn{1}{c|}{2002} & \multicolumn{1}{c|}{2003} & \multicolumn{1}{c|}{2004} & \multicolumn{1}{c|}{ Total } \\
\hline $1.509,6$ & 35,8 & 42,9 & 41,8 & 36,3 & 37,3 & 45,1 & 1.749 \\
\hline
\end{tabular}

Fuente: Instituto para la Diversificación y Ahorro de la Energía. Plan de Energías Renovables en España 2005-2010.

En enero de 2011, la Agencia Estatal de Evaluación de las Políticas Públicas y la Calidad de los Servicios publica el documento Evaluación del Plan Español de Energías Renovables 2005-2010. En el Cuadro $N^{\circ} 6$ se expone el seguimiento de la potencia instalada y de la producción eléctrica. 
Cuadro No 6

Potencia instalada (MW) y producción eléctrica $(\mathrm{GWH})$ en minicentrales hidroeléctricas. 2005-2010

\begin{tabular}{|l|l|r|r|r|r|r|r|r|}
\hline $\begin{array}{l}\text { Objetivo } \\
2010\end{array}$ & 2005 & 2006 & 2007 & 2008 & 2009 & 2010 & $\begin{array}{r}\text { Acumulado } \\
2005-2010\end{array}$ \\
\hline \multirow{2}{*}{$\begin{array}{l}\text { Potencia } \\
\text { MW }\end{array}$} & Previsiones PER & 70,0 & 70,0 & 70,0 & 80,0 & 80,0 & 80,0 & 450,0 \\
\cline { 2 - 9 } 2.199 & Real & 51,1 & 30,6 & 31,2 & 28,6 & 25,1 & 6,0 & 173,0 \\
\cline { 2 - 9 } & \% objetivo & $-27,0$ & $-56,3$ & $-55,4$ & 64,3 & 68,6 & $-92,5$ & $-61,6$ \\
\hline \multirow{2}{*}{$\begin{array}{l}\text { Producción } \\
\text { GWh } \\
3.257\end{array}$} & Previsiones PER & 109,0 & 326,0 & 543,0 & 775,0 & $1.023,0$ & $1.271,0$ & - \\
\cline { 2 - 9 } & Real & 77,7 & 202,7 & 297,8 & 297,8 & 494,1 & 585,1 & - \\
\cline { 2 - 8 } & \% objetivo & $-28,7$ & $-37,8$ & $-45,2$ & $-50,7$ & $-21,7$ & $-54,0$ & - \\
\hline
\end{tabular}

Fuente: Agencia Estatal de Evaluación de las Políticas Públicas y la Calidad de los Servicios.

Para los redactores del documento, el déficit de cumplimiento de los objetivos observado se debe a la dificultad de carácter administrativo para el procedimiento de concesiones. También se reconoce que pudieron haberse establecido unos objetivos en exceso ambiciosos para una fuente de energía de la que no existían previsiones razonables de aumento de potencia (aunque no se dispone de estudio alguno que evalúe la capacidad de aprovechamiento hidroeléctrico de las cuencas hidrográficas). Sobre la voluntad política para la aplicación de las medidas que lleven a la consecución de los objetivos, desde el ámbito empresarial se asegura que no existe apoyo político, pese al reducido impacto ecológico de la centrales; mientras que las organizaciones ecologistas señalan impactos ambientales sensibles en ciertos proyectos planteados, y se percibe, en este mismo sentido, un cierto rechazo social a estas instalaciones, lo cual deriva en una mayor dificultad de encontrar emplazamientos adecuados, y en la menor rentabilidad diferencial en relación con otras inversiones en el terreno de las energías renovables. Por último, se acusa a las grandes empresas eléctricas de obtener concesiones para instalaciones de minihidráulica que no utilizan, perjudicando así a los pequeños productores (Agencia de Evaluación y Calidad, 2011).

Por último, según el Plan de Energías Renovables 2011-2020 (PER 2011-2020), las energías renovables han de cubrir en el año 2020 como mínimo el 20\% del consumo final bruto de energía, en línea con los objetivos marcados por la Directiva 2009/28/CE. Este porcentaje supone un consumo del $39 \%$ sobre el total del consumo eléctrico. Se estima que se produzcan incrementos de potencia media anuales de 25 MW, para llegar a 2020 con un aumento de 254 MW, 24 para las centrales de menos de $1 \mathrm{MW}$ y $230 \mathrm{MW}$ para las de 1 a $10 \mathrm{MW}$.

\section{El marco legislativo}

El marco legislativo es el que ha marcado el régimen económico de la producción de electricidad con esta tecnología (Cuadro No 7), y por tanto su impulso durante décadas y la moratoria y descenso del nivel de ingresos que padecen en la actualidad respecto a las fechas en las que se pusieron en marcha los proyectos. 


\section{Cuadro No 7}

El marco legislativo. Desarrollo de las energías renovables

\begin{tabular}{|c|c|}
\hline Ley/RD & Estrategias / Objetivos \\
\hline $\begin{array}{l}\text { Ley } 82 / 1980 \text {, de } 30 \\
\text { de diciembre, sobre } \\
\text { Conservación de } \\
\text { Energía }\end{array}$ & $\begin{array}{l}\text { Potencia la adopción de fuentes de energía renovables reduciendo en } \\
\text { lo posible el consumo de hidrocarburos y la dependencia exterior de } \\
\text { los combustibles. } \\
\text { Fomenta la autogeneración de energía eléctrica y la producción hi- } \\
\text { droeléctrica. }\end{array}$ \\
\hline $\begin{array}{l}\text { R.D. } 1217 / 1981 \text {, de } 10 \\
\text { de abril }\end{array}$ & Fomenta la producción hidroeléctrica en pequeñas centrales. \\
\hline $\begin{array}{l}\text { R.D. } 907 / 1982 \text { de } 2 \text { de } \\
\text { abril }\end{array}$ & $\begin{array}{l}\text { Fomenta la autogeneración eléctrica. } \\
\text { Establece las características para obtener la condición de autogenera- } \\
\text { dores eléctricos. }\end{array}$ \\
\hline $\begin{array}{l}\text { R.D. } 1544 / 1982 \text {, de } 25 \\
\text { de junio }\end{array}$ & $\begin{array}{l}\text { Fomenta la construcción de centrales hidroeléctricas. } \\
\text { Regula las centrales de potencia superior a los } 5 \text { MW. }\end{array}$ \\
\hline $\begin{array}{l}\text { Orden de } 28 \text { de julio } \\
\text { de } 1982\end{array}$ & Desarrolla el Real Decreto 1217/1981, de 10 de abril. \\
\hline $\begin{array}{l}\text { R.D. } 916 / 1985 \text {, de } 25 \\
\text { de mayo }\end{array}$ & $\begin{array}{l}\text { Establece un procedimiento abreviado de tramitación de concesiones } \\
\text { y autorizaciones administrativas para la instalación, ampliación o adap- } \\
\text { tación de aprovechamientos hidroeléctricos con potencia nominal no } \\
\text { superior a los } 5.000 \mathrm{~kW} \text {. }\end{array}$ \\
\hline $\begin{array}{l}\text { R.D. } 249 / 1988 \text {, de } 18 \\
\text { de marzo }\end{array}$ & $\begin{array}{l}\text { Modifica los artículos } 2^{\circ}, 9^{\circ} \text { y } 14^{\circ} \text { del Real Decreto } 916 / 1985 \text {. } \\
\text { Reconoce que ha venido cumpliendo sus objetivos, pero en los últimos } \\
\text { meses de su aplicación se ha producido un inesperado incremento de } \\
\text { peticiones, lo que aconseja la prudencia en las concesiones. } \\
\text { Sugiere, ante la proximidad de los Planes Hidrológicos, la convenien- } \\
\text { cia de adoptar una mayor actitud cautelar en la tramitación del expe- } \\
\text { diente. }\end{array}$ \\
\hline $\begin{array}{l}\text { Ley } 54 / 1997, \text { del } \\
\text { Sector Eléctrico, de } 27 \\
\text { de noviembre }\end{array}$ & $\begin{array}{l}\text { Mejora la eficiencia energética, la reducción del consumo y la protec- } \\
\text { ción del medio ambiente, necesarios en función de los compromisos } \\
\text { adquiridos por España en la reducción de gases de efecto invernadero. }\end{array}$ \\
\hline $\begin{array}{l}\text { R.D. } 2818 / 1998 \text {, de } 23 \\
\text { de diciembre }\end{array}$ & $\begin{array}{l}\text { Establece un sistema de incentivos temporales para las instalaciones } \\
\text { con potencia instalada inferior o igual a } 50 \mathrm{MW} \text {. }\end{array}$ \\
\hline $\begin{array}{l}\text { R.D.-Ley } 6 / 2000, \text { de } \\
24 \text { de junio }\end{array}$ & $\begin{array}{l}\text { Establece Medidas Urgentes de Intensificación de la Competencia en } \\
\text { Mercados de Bienes y Servicios. } \\
\text { Incentiva la participación en el mercado de las instalaciones del régi- } \\
\text { men especial, previendo la posibilidad de contratos de venta de ener- } \\
\text { gía con comercializadores. }\end{array}$ \\
\hline $\begin{array}{l}\text { R.D. } 841 / 2002 \text {, de } 2 \text { de } \\
\text { agosto }\end{array}$ & $\begin{array}{l}\text { Desarrolla el Real Decreto Ley } 6 / 2000 \text {, y establece la obligatoriedad de } \\
\text { participación en el mercado para las instalaciones de potencia superior } \\
\text { a los } 50 \mathrm{MW} \text {. } \\
\text { Incentiva la participación en el mercado de producción de las instala- } \\
\text { ciones de producción de energía eléctrica en régimen especial. }\end{array}$ \\
\hline
\end{tabular}


Continuación Cuadro No 7

\begin{tabular}{|l|l|}
\hline Ley/RD & \multicolumn{1}{c|}{ Estrategias / Objetivos } \\
\hline $\begin{array}{l}\text { R.D. 436/2004, de 12 } \\
\text { de marzo }\end{array}$ & $\begin{array}{l}\text { Establece la metodología para la actualización y sistematización del ré- } \\
\text { gimen jurídico y económico de la actividad de producción de energía } \\
\text { eléctrica en régimen especial y establece un esquema legal y económi- } \\
\text { co para el régimen especial. }\end{array}$ \\
\hline $\begin{array}{l}\text { R.D.-Ley 7/2006, de 23 } \\
\text { de junio }\end{array}$ & $\begin{array}{l}\text { Adopta medidas urgentes en el sector energético, desvinculando la va- } \\
\text { riación de la primas del régimen especial de la tarifa media eléctrica o } \\
\text { de referencia. }\end{array}$ \\
\hline R.D. 661/2007, de 25 25 & $\begin{array}{l}\text { Regula la producción de energía eléctrica en régimen especial, y dero- } \\
\text { ga el decreto 436/2004, pero conservando su esquema básico: venta } \\
\text { a tarifa regulada, que es el precio fijo que recibe el productor por la } \\
\text { energía vendida al sistema, o directamente en el mercado, percibiendo } \\
\text { el precio negociado en el mismo más una prima. } \\
\text { Mantiene el límite de potencia para acceder a la retribución de este } \\
\text { Real Decreto en los 2.400 MW en centrales hidráulicas de hasta 10 MW. }\end{array}$ \\
\hline
\end{tabular}

Fuente: Elaboración propia basado en datos del Boletín Oficial del Estado.

Para el Gobierno de España, el crecimiento del déficit tarifario en la primavera de 2009 estaba produciendo graves problemas, poniendo en riesgo, no solo la situación financiera de las empresas del sector eléctrico, sino la sostenibilidad misma del sistema. Es entonces cuando el Gobierno se plantea un cambio en sus planteamientos cuyo objetivo es la contención del desarrollo del sector (Cuadro No 8).

\section{Cuadro No 8}

El marco legislativo. Del inicio de la contención al crecimiento de las energías renovables

\begin{tabular}{|c|c|}
\hline Ley/RD & Estrategias / Objetivos \\
\hline $\begin{array}{l}\text { R.D.-Ley 6/2009, de } 30 \\
\text { de abril }\end{array}$ & $\begin{array}{l}\text { Adopta determinadas medidas en el sector eléctrico y aprueba el bono } \\
\text { social. } \\
\text { Crea un Registro de Preasignación de retribución que permite conocer } \\
\text { los proyectos que cumplen con las condiciones para poder ejecutarse, } \\
\text { su volumen de potencia, el impacto en los costes de la tarifa eléctrica } \\
\text { y su calendario. La inscripción en el Registro es una condición necesa- } \\
\text { ria para obtener el régimen económico establecido en el Real Decreto } \\
661 / 2007 \text {. } \\
\text { Prevé un régimen transitorio para garantizar la seguridad jurídica de } \\
\text { quienes habían realizado inversiones bajo el amparo de este Real De- } \\
\text { creto antes de la entrada en vigor del Real Decreto-Ley } 6 / 2009 \text {. Cuando } \\
\text { la potencia inscrita sea inferior al objetivo previsto en el Real Decreto } \\
661 / 2007, \text { como sucede con la minihidráulica, el régimen económico } \\
\text { previsto en el mismo se extenderá hasta su cumplimiento. }\end{array}$ \\
\hline
\end{tabular}


Continuación Cuadro No 8

\begin{tabular}{|l|l|}
\hline Ley/RD & \multicolumn{1}{|c|}{ Estrategias / Objetivos } \\
\hline $\begin{array}{l}\text { R.D. 1565/2010, de 19 } \\
\text { de noviembre }\end{array}$ & $\begin{array}{l}\text { Regula y modifica determinados aspectos relativos a la actividad de } \\
\text { producción de energía eléctrica en régimen especial. } \\
\text { Se elimina el pago de energía primada durante los 25 primeros años de } \\
\text { la instalación, establecido en el R.D. 661/2007. }\end{array}$ \\
\hline R.D.-Ley 14/2010 & $\begin{array}{l}\text { Modifica retroactivamente todas las tarifas reguladas e instauradas en } \\
\text { el R.D. 661/2007. }\end{array}$ \\
\hline
\end{tabular}

Fuente: Elaboración propia basado en datos del Boletín Oficial del Estado.

No acaban aquí las medidas de contención y limitación al crecimiento de las energías renovables en España. Hasta finales de la primera década de este siglo, la normativa que han ido aprobando los Gobiernos de España en relación a las energías renovables se ha destinado a su desarrollo y fomento. Sin embargo, la crisis económica y la tendencia creciente del déficit de tarifa del sector eléctrico han provocado que las medidas del Gobierno a partir de principios de 2012 estén orientadas a la reducción del coste que suponen estas tecnologías al sistema. Tras establecerse medidas urgentes en 2012, unos meses más tarde, en 2013, se continuó con la reforma eléctrica (Cuadro No 9).

\section{Cuadro $\mathrm{N}^{\circ} 9$}

El marco legislativo. Contención y limitación. La reforma eléctrica

\begin{tabular}{|l|l|}
\hline Ley/RD & \multicolumn{1}{|c|}{ Estrategias / Objetivos } \\
\hline $\begin{array}{l}\text { R.D. 1/2012, de 27 de } \\
\text { enero }\end{array}$ & $\begin{array}{l}\text { Suspende los procedimientos de pre-asignación de retribución y los } \\
\text { incentivos económicos para nuevas instalaciones del régimen especial }\end{array}$ \\
\hline $\begin{array}{l}\text { R.D.-Ley 13/2012, de } \\
30 \text { de marzo }\end{array}$ & $\begin{array}{l}\text { Establece medidas para garantizar la estabilidad presupuestaria y de } \\
\text { fomento de la competitividad. }\end{array}$ \\
\hline $\begin{array}{l}\text { R.D.-Ley 20/2012, de } \\
13 \text { de julio }\end{array}$ & $\begin{array}{l}\text { Establece medidas para garantizar la estabilidad presupuestaria y de } \\
\text { fomento de la competitividad. }\end{array}$ \\
\hline $\begin{array}{l}\text { Ley 15/2012, de 27 de } \\
\text { diciembre }\end{array}$ & $\begin{array}{l}\text { Adopta medidas fiscales para la sostenibilidad energética (nuevos im- } \\
\text { puestos con fines recaudatorios con la intención de reducir el déficit } \\
\text { eléctrico, e impuesto sobre el valor de la producción energética que } \\
\text { grava la generación y la incorporación de la energía al sistema eléctri- } \\
\text { co con un tipo impositivo de un 7\%). } \\
\text { Se modifica el texto refundido de la Ley de Aguas (R.D. Legislativo } \\
\text { 1/2001, de 20 de julio), para establecer un canon por la utilización de } \\
\text { aguas continentales para la producción de energía eléctrica con un } \\
\text { tipo impositivo de un 22\%, el cual se reduce un 90\% en centrales hi- } \\
\text { droeléctricas iguales o inferiores a 50 MW. }\end{array}$ \\
\hline $\begin{array}{l}\text { Rretende eliminar el déficit tarifario en 2012 y 2013. } \\
\text { 28 de diciembre }\end{array}$ & \multicolumn{2}{|c|}{} \\
\hline
\end{tabular}


Continuación Cuadro No 9

\begin{tabular}{|c|c|}
\hline Ley/RD & Estrategias / Objetivos \\
\hline $\begin{array}{l}\text { El Real Decreto- } \\
\text { Ley } 2 / 2013 \text {, de } 1 \text { de } \\
\text { febrero }\end{array}$ & $\begin{array}{l}\text { Establece medidas urgentes en el sistema eléctrico y en el sector fi- } \\
\text { nanciero. } \\
\text { Sustituye la metodología por la que se actualizan las retribuciones, } \\
\text { tarifas y primas de las actividades del sistema eléctrico vinculadas al } \\
\text { Índice de Precios al Consumo (IPC), y sustituye este índice por el Ín- } \\
\text { dice de Precios Constantes sin alimentos no elaborados ni productos } \\
\text { energéticos, que son los más volátiles. } \\
\text { Modifica el R.D. } 661 / 2007 \text {, con el que se regula la actividad de produc- } \\
\text { ción eléctrica en régimen especial, suprimiendo las primas existentes. }\end{array}$ \\
\hline $\begin{array}{l}\text { Orden IET/221/2013, } \\
\text { de } 14 \text { de febrero }\end{array}$ & $\begin{array}{l}\text { Establece un nuevo régimen jurídico y económico para las instalacio- } \\
\text { nes de producción de energía eléctrica a partir de energías renovables, } \\
\text { cogeneración y residuos. } \\
\text { Se abandona el modelo basado en la producción eléctrica establecido } \\
\text { desde la Ley 54/1997. } \\
\text { Desaparece el régimen especial y pasan todas las instalaciones a re- } \\
\text { girse por la misma normativa y asumir las obligaciones del mercado. } \\
\text { Se establecen los peajes de acceso a partir del } 1 \text { de enero de } 2013 \text { y las } \\
\text { tarifas y primas de las instalaciones del régimen especial. }\end{array}$ \\
\hline $\begin{array}{l}\text { R.D.-Ley } 9 / 2013 \text {, de } 12 \\
\text { de julio }\end{array}$ & $\begin{array}{l}\text { Adopta medidas urgentes para garantizar la estabilidad financiera del } \\
\text { sector eléctrico. }\end{array}$ \\
\hline $\begin{array}{l}\text { Ley } 24 / 2013 \text {, de } 26 \text { de } \\
\text { diciembre, del Sector } \\
\text { Eléctrico }\end{array}$ & Confirma los principios del R.D.-Ley 9/2013, de 12 de julio. \\
\hline $\begin{array}{l}\text { Real Decreto } \\
413 / 2014 \text {, de } 6 \text { de } \\
\text { junio }\end{array}$ & $\begin{array}{l}\text { Desarrolla el Real Decreto-Ley 9/2013. } \\
\text { Regula la actividad de producción de energía eléctrica a partir de fuen- } \\
\text { tes de energías renovables, cogeneración y residuos. }\end{array}$ \\
\hline $\begin{array}{l}\text { Orden IET/1045/2014, } \\
\text { de } 16 \text { de junio }\end{array}$ & $\begin{array}{l}\text { Se aprueban los parámetros retributivos de las instalaciones tipo apli- } \\
\text { cables a determinadas instalaciones a partir de fuentes de energías } \\
\text { renovables, cogeneración y residuos. } \\
\text { Se indica la retribución a la operación y la retribución a la inversión } \\
\text { para el primer semiperiodo regulatorio que termina en } 2016 \text { para todas } \\
\text { las instalaciones tipo. }\end{array}$ \\
\hline $\begin{array}{l}\text { Orden IET/1345/2015, } \\
\text { de } 2 \text { de julio }\end{array}$ & $\begin{array}{l}\text { Establece la metodología de actualización de la retribución a la opera- } \\
\text { ción de las instalaciones con régimen retributivo específico. }\end{array}$ \\
\hline
\end{tabular}

Fuente: Elaboración propia basado en datos del Boletín Oficial del Estado.

\section{El resurgimiento de la energía minihidráulica}

La crisis energética de 1973, unida a una progresiva concienciación de la sociedad sobre la necesidad de preservar y mejorar las condiciones ambientales, propicia el desarrollo de la política energética que fomenta la investigación y desarrollo de las energías renovables (Sánchez, 1994). 
Como resultado de esta política, en los años ochenta se acometieron la rehabilitación y acondicionamiento de antiguas minicentrales, así como la construcción de otras nuevas, en un conjunto de actuaciones que se presentan en el Cuadro $N^{\circ} 10$. Como ha ocurrido en otras ocasiones, la posibilidad de un negocio fácil determinó un nuevo interés por las minicentrales. Al amparo de la Ley de Conservación de la Energía se presentaron cientos de solicitudes de concesión, muchas de ellas sin estar avaladas por un estudio hidrológico suficiente (Domínguez, 1994a).

\section{Cuadro No 10}

Actuaciones del sector eléctrico en el área de pequeñas centrales hidroeléctricas, 1981-1989

\begin{tabular}{|l|r|r|r|r|}
\hline & \multicolumn{1}{|c|}{$\begin{array}{c}\text { Potencia } \\
\text { MW }\end{array}$} & $\begin{array}{c}\text { Producción total } \\
\text { anual } \\
\text { GWh }\end{array}$ & $\begin{array}{c}\text { Incremento de } \\
\text { Producción } \\
\text { anual GWh }\end{array}$ & \multicolumn{1}{|c|}{$\begin{array}{c}\text { Inversión } \\
\text { Millones de } \\
\text { pesetas }\end{array}$} \\
\hline Recuperación & 3,972 & 18,700 & 18,700 & 916 \\
\hline Modernización & 136,979 & 534,395 & 49,782 & 2.244 \\
\hline Ampliación & 13,325 & 50,300 & 50,300 & 2.845 \\
\hline Nueva construcción & 31,887 & 152,294 & 152,294 & 71.335 \\
\hline Total & 186,163 & 755,689 & 271,076 & 148.675 \\
\hline
\end{tabular}

Fuente: Pérez, 2002; Domínguez, 1994a.

Durante el periodo de vigencia del Plan de Energías Renovables 1986-1988 se pusieron en marcha 105 centrales, con una potencia de $54 \mathrm{MW}$, una producción media de $259 \mathrm{GWh} / \mathrm{año,} \mathrm{y}$ una inversión de 8.150 millones de pesetas. Entre los años 1989 y 1990, con el segundo Plan de Energías Renovables (1989-1995) en vigor, se pusieron en marcha en España un total de 82 minicentrales hidroeléctricas, que supusieron un incremento de $94 \mathrm{MW}$ en la potencia instalada y una producción estimada en año y medio de $353 \mathrm{GWh} /$ año. La inversión fue de 12.685 millones de pesetas. En conjunto (1986-1990), las centrales puestas en funcionamiento ascienden a 187, con

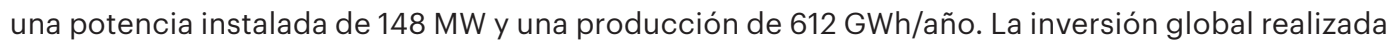
fue de 20.835 millones de pesetas (Sánchez, 1994).

De estas 187 minicentrales, 167 son fluyentes, 7 son de pie de presa y 13 están situadas en canales de riego u otros usos. El 74\% corresponde a centrales rehabilitadas, el 12\% son de nueva construcción y el $19 \%$ restante corresponden a ampliaciones de centrales ya existentes. La distribución de estas centrales por Comunidades Autónomas queda recogida en el Cuadro No 11 (Sánchez, 1994).

\section{Cuadro No 11}

Distribución por Comunidades Autónomas de las minicentrales puestas en marcha, potencia y producción, 1986-1990

\begin{tabular}{|l|r|r|r|}
\hline Comunidad Autónoma & Número & Potencia MW & Producción anual GWh \\
\hline Andalucía & 8 & 25,0 & 75,4 \\
\hline Aragón & 15 & 21,0 & 87,5 \\
\hline Asturias & 3 & 0,9 & 5,9 \\
\hline
\end{tabular}


Continuación Cuadro No 11

\begin{tabular}{|l|r|r|r|}
\hline Comunidad Autónoma & Número & Potencia MW & Producción anual GWh \\
\hline Canarias & 3 & 0,2 & 1,7 \\
\hline Cantabria & 1 & 0,3 & 1,2 \\
\hline Castilla-La Mancha & 8 & 5,5 & 23,5 \\
\hline Castilla y León & 30 & 25,0 & 106,5 \\
\hline Cataluña & 46 & 15,0 & 79,1 \\
\hline C. Valenciana & 2 & 1,3 & 7,2 \\
\hline Extremadura & 2 & 0,7 & 3,9 \\
\hline Galicia & 19 & 20,0 & 76,2 \\
\hline La Rioja & 3 & 8,0 & 29,3 \\
\hline Madrid & 2 & 1,0 & 5,1 \\
\hline Navarra & 21 & 16,0 & 63,5 \\
\hline País Vasco & 24 & 8,9 & 45,0 \\
\hline Total & 187 & 148,0 & 612,0 \\
\hline
\end{tabular}

Fuente: Sánchez, 1994.

Durante la década de los noventa, entre 1991 y 1997, se ponen en marcha otras 273 centrales que suman una potencia de $455 \mathrm{MW}$ (Cuadro No 12). Según tamaño, predominan las de menos de $1 \mathrm{MW}$, que suponen más de la mitad (51,6\%), seguidas de las de 1-5 MW $(41,4 \%)$. Las incluidas en este intervalo son las que suman mayor potencia instalada con el $62,5 \%$, y a continuación las de 5-10 MW, que aportan el 25,7\%.

\section{Cuadro No 12}

Número de minicentrales puestas en funcionamiento. 1991-1997

\begin{tabular}{|l|r|r|r|r|r|r|r|r|}
\hline & \multicolumn{4}{|c|}{ CENTRALES } & \multicolumn{4}{|c|}{ POTENCIA MW } \\
\cline { 2 - 9 } & $\begin{array}{l}\text { Menos } \\
\text { de 1 MW }\end{array}$ & $\begin{array}{c}1-5 \\
\text { MW }\end{array}$ & $\begin{array}{c}5-10 \\
\text { MW }\end{array}$ & Total & $\begin{array}{c}\text { Menos } \\
\text { de 1 MW }\end{array}$ & $\begin{array}{c}1-5 \\
\text { MW }\end{array}$ & $\begin{array}{c}5-10 \\
\text { MW }\end{array}$ & \multicolumn{1}{c|}{ Total } \\
\hline 1991 & 21 & 16 & 1 & 38 & 9,22 & 47,83 & 5,00 & 62,05 \\
\hline 1992 & 44 & 30 & 5 & 79 & 18,51 & 64,43 & 26,60 & 109,54 \\
\hline 1993 & 23 & 22 & 3 & 48 & 8,80 & 65,46 & 19,56 & 93,82 \\
\hline 1994 & 7 & 10 & 4 & 21 & 2,10 & 25,50 & 27,00 & 54,60 \\
\hline 1995 & 16 & 13 & 3 & 32 & 6,33 & 36,91 & 21,69 & 64,93 \\
\hline 1996 & 12 & 10 & 3 & 25 & 3,42 & 19,60 & 17,00 & 40,02 \\
\hline 1997 & 18 & 12 & 0 & 30 & 5,33 & 24,63 & 0,00 & 29,96 \\
\hline $1991-1997$ & 141 & 113 & 19 & 273 & 53,71 & 284,36 & 116,85 & 454,92 \\
\hline
\end{tabular}

Fuente: Instituto para la Diversificación y Ahorro de la Energía. Las energías renovables en España. Balance y perspectiva 2000. Edición 98. 
A finales de 1997 se aprueba la Ley del Sector Eléctrico, y esta Ley lleva a la promulgación del Real Decreto 2818/1998, de 23 de diciembre, sobre producción de energía eléctrica por instalaciones abastecidas por recursos o fuentes de energía renovables, residuos y cogeneración, que son las incluidas en el régimen especial, y se establece un sistema de incentivos temporales para las instalaciones que requieren de ellos para situarse en posición de competencia en un mercado libre (Cuadro No 7). En el caso de las energías renovables y de residuos, el incentivo establecido no tiene límite temporal. Se pueden acoger al régimen especial las instalaciones con potencia instalada inferior o igual a $50 \mathrm{MW}$, distinguiendo entre centrales hidroeléctricas cuya potencia sea inferior a los $10 \mathrm{MW}$ y las que oscilen entre 10 y $50 \mathrm{MW}$ (Espejo, 2005).

Desde 1998, la Comisión Nacional de Energía, hoy denominada Comisión Nacional de los Mercados y la Competencia, elabora la Estadística de Venta de Energía en Régimen Especial, que incluye por Comunidades Autónomas todas las centrales hidroeléctricas con una potencia de hasta 50 MW. En nuestro caso, como nos interesa la evolución de la minihidráulica, hemos confeccionado los Cuadros №13, № 14 y No 15 para comparar la situación entre 1998 y 2013, último año que ha sido posible disponer de información, ya que para 2014 y 2015 los datos se refieren al total de centrales con hasta $50 \mathrm{MW}$. No obstante, del análisis de estos últimos datos se desprende que en 2014 no se inaugura ninguna central incluida en este intervalo de potencia, y en 2015 únicamente 4 ( 2 en Cataluña, 1 en Castilla y León, y 1 en Murcia), que suman una potencia de 6 MW, con lo que se confirma la casi paralización del sector como consecuencia de las medidas adoptadas por el Gobierno de España y por la incidencia de la nueva Ley del Sector Eléctrico de 2013.

\section{Cuadro No 13}

Centrales minihidráulicas en las Comunidades Autónomas, 1998 y 2013

\begin{tabular}{|c|c|c|c|c|c|c|c|c|c|c|}
\hline & \multicolumn{4}{|c|}{1998} & \multicolumn{4}{|c|}{2013} & \multicolumn{2}{|c|}{ 1998-2013 } \\
\hline & $\begin{array}{c}\text { Menos } \\
\text { de } 1 \\
\text { MW }\end{array}$ & $\begin{array}{l}1-5 \\
M W\end{array}$ & $\begin{array}{l}5-10 \\
M W\end{array}$ & Total & $\begin{array}{c}\text { Menos } \\
\text { de } 1 \\
\text { MW }\end{array}$ & $\begin{array}{l}1-5 \\
M W\end{array}$ & $\begin{array}{l}5-10 \\
\text { MW }\end{array}$ & Total & $\begin{array}{c}\text { Centrales } \\
\text { creadas }\end{array}$ & $\begin{array}{c}\text { Crecimiento } \\
(\%)\end{array}$ \\
\hline Andalucía & 4 & 15 & 4 & 23 & 8 & 16 & 7 & 31 & 8 & 34,8 \\
\hline Aragón & 9 & 9 & 11 & 29 & 18 & 22 & 7 & 47 & 18 & 62, \\
\hline Asturias & 1 & 7 & 2 & 10 & 4 & 7 & 3 & 14 & 4 & 40,0 \\
\hline Canarias & 1 & & & 1 & 1 & & & 1 & 0 & 0,0 \\
\hline Cantabria & 3 & 3 & 2 & 8 & 8 & 10 & 6 & 24 & 16 & 200,0 \\
\hline $\begin{array}{l}\text { Castilla-La } \\
\text { Mancha }\end{array}$ & 9 & 20 & 2 & 31 & 15 & 26 & 3 & 44 & 13 & 41,9 \\
\hline $\begin{array}{l}\text { Castilla y } \\
\text { León }\end{array}$ & 42 & 25 & 6 & 73 & 72 & 83 & 52 & 207 & 134 & 183,6 \\
\hline Cataluña & 46 & 40 & 9 & 95 & 83 & 49 & 10 & 142 & 47 & 49,5 \\
\hline $\begin{array}{l}\text { Comunidad } \\
\text { Valenciana }\end{array}$ & 2 & 2 & & 4 & 2 & 3 & & 5 & 1 & 25,0 \\
\hline Extremadura & 1 & 2 & 1 & 4 & 4 & 3 & 5 & 12 & 8 & 200,0 \\
\hline Galicia & 15 & 22 & 8 & 45 & 26 & 38 & 17 & 81 & 36 & 80,0 \\
\hline La Rioja & 6 & 6 & 1 & 13 & 13 & 9 & 8 & 30 & 17 & 130,8 \\
\hline Madrid & 2 & 4 & 1 & 7 & 7 & 4 & 4 & 15 & 8 & 114,3 \\
\hline
\end{tabular}


Continuación Cuadro No 13

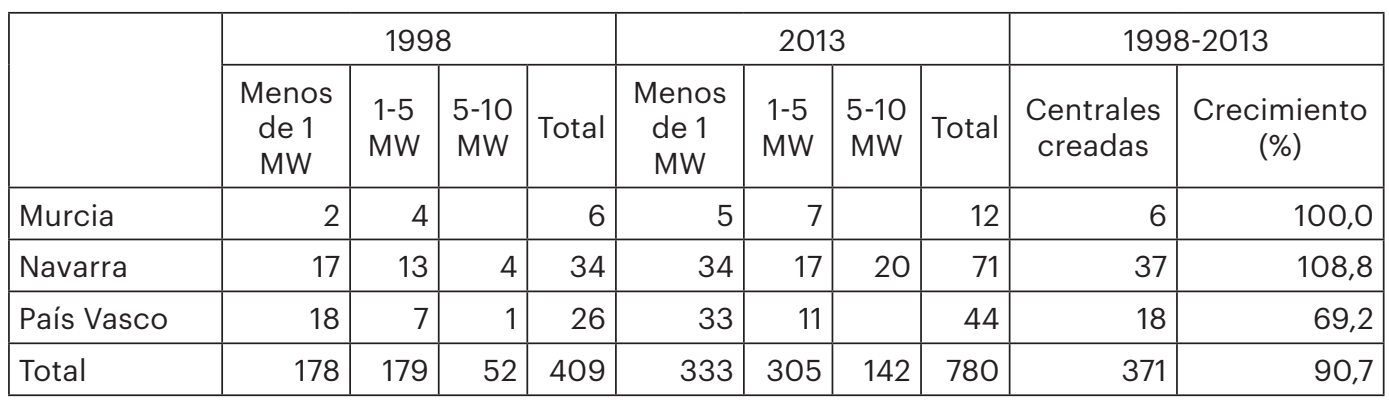

Fuente: Comisión Nacional de Energía.

\section{Cuadro No 14}

Potencia instalada en centrales minihidráulicas en las comunidades autónomas MW, 1998 y 2013

\begin{tabular}{|c|c|c|c|c|c|c|c|c|c|c|}
\hline & \multicolumn{4}{|c|}{1998} & \multicolumn{4}{|c|}{2013} & \multicolumn{2}{|c|}{ 1998-2013 } \\
\hline & $\begin{array}{c}\text { Menos } \\
\text { de } 1 \\
\text { MW }\end{array}$ & $\begin{array}{l}1-5 \\
M W\end{array}$ & $\begin{array}{l}5-10 \\
\text { MW }\end{array}$ & Total & $\begin{array}{c}\text { Menos } \\
\text { de } 1 \\
\text { MW }\end{array}$ & $\begin{array}{l}1-5 \\
M W\end{array}$ & $\begin{array}{l}5-10 \\
\text { MW }\end{array}$ & Total & $\begin{array}{c}\text { Aumento } \\
\text { Potencia } \\
\text { MW }\end{array}$ & $\begin{array}{c}\text { Crecimiento } \\
(\%)\end{array}$ \\
\hline Andalucía & 2,89 & 43,07 & 29,09 & 75,05 & 5,79 & 47,74 & 44,86 & 98,39 & 23,34 & 31,1 \\
\hline Aragón & 3,6 & 21,05 & 71,43 & 96,08 & 4,51 & 52,39 & 43,04 & 99,94 & 3,86 & 4,0 \\
\hline Asturias & 0,05 & 15,09 & 7,00 & 22,14 & 1,47 & 17,19 & 17,00 & 35,66 & 13,52 & 61,1 \\
\hline Canarias & 0,46 & - & - & 0,46 & 0,46 & - & - & 0,46 & 0 & 0,0 \\
\hline Cantabria & 1,2 & 4,97 & 11,72 & 17,89 & 4,12 & 14,45 & 25,75 & 44,32 & 26,43 & 147,7 \\
\hline $\begin{array}{l}\text { Castilla-La } \\
\text { Mancha }\end{array}$ & 3,57 & 40,21 & 10,76 & 54,54 & 4,59 & 54,85 & 21,56 & 81,00 & 26,46 & 48,5 \\
\hline $\begin{array}{l}\text { Castilla y } \\
\text { León }\end{array}$ & 13,47 & 59,18 & 40,72 & 113,37 & 29,05 & 111,96 & 65,25 & 206,26 & 92,89 & 81,9 \\
\hline Cataluña & 14,44 & 80,08 & 63,89 & 158,41 & 26,33 & 104,68 & 69,77 & 200,78 & 42,37 & 26,7 \\
\hline $\begin{array}{l}\text { Comunidad } \\
\text { Valenciana }\end{array}$ & 1,13 & 5,52 & - & 6,65 & 1,13 & 9,79 & - & 10,92 & 4,27 & 64,2 \\
\hline Extremadura & 0,18 & 3,35 & 9,14 & 12,67 & 1,77 & 8,65 & 9,14 & 19,56 & 6,89 & 54,4 \\
\hline Galicia & 6,42 & 51,06 & 47,60 & 105,08 & 11,53 & 99,18 & 127,39 & 238,10 & 133,02 & 126,6 \\
\hline La Rioja & 0,69 & 11,14 & 7,61 & 19,44 & 1,27 & 18,11 & 7,62 & 27,00 & 7,56 & 38,9 \\
\hline Madrid & 1,44 & 11,92 & 7,20 & 20,56 & 1,83 & 12,16 & 8,64 & 22,63 & 2,07 & 10,1 \\
\hline Murcia & 1,15 & 9,78 & - & 10,93 & 2,73 & 11,26 & - & 13,99 & 3,06 & 28,0 \\
\hline Navarra & 8,38 & 34,23 & 23,22 & 65,83 & 7,10 & 43,62 & 41,57 & 92,29 & 26,46 & 40,2 \\
\hline País Vasco & 5,80 & 15,53 & 5,48 & 26,81 & 11,15 & 28,41 & - & 39,56 & 12,75 & 47,6 \\
\hline Total & 64,87 & 406,18 & 334,86 & 805,91 & 114,83 & 634,44 & 481,59 & $1.230,86$ & 424,95 & 52,7 \\
\hline
\end{tabular}

Fuente: Comisión Nacional de Energía. 
Cuadro No 15

Producción de electricidad en centrales minihidráulicas en las Comunidades Autónomas GWH, 1998 y 2013

\begin{tabular}{|l|r|r|r|r|r|r|r|r|r|r|}
\hline & \multicolumn{4}{|c|}{1998} & \multicolumn{2}{|c|}{2013} & \multicolumn{2}{|c|}{$1989-2013$} \\
\hline & $\begin{array}{c}\text { Menos } \\
\text { de } \\
\text { MW }\end{array}$ & $\begin{array}{c}1-5 \\
\text { MW }\end{array}$ & $\begin{array}{c}5-10 \\
\text { MW }\end{array}$ & Total & $\begin{array}{c}\text { Menos } \\
\text { de } 1 \\
\text { MW }\end{array}$ & $1-5$ MW & $\begin{array}{c}5-10 \\
\text { MW }\end{array}$ & Total & $\begin{array}{c}\text { Aumento } \\
\text { producción } \\
\text { GWh }\end{array}$ & $\begin{array}{c}\text { Crecimiento } \\
\text { (\%) }\end{array}$ \\
\hline Andalucía & 16,11 & 109,84 & 74,71 & 200,66 & 19,69 & 99,07 & 87,23 & 205,99 & 5,33 & 2,7 \\
\hline Aragón & 11,97 & 39,44 & 349,63 & 401,04 & 14,28 & 180,78 & 181,86 & 376,92 & $-24,12$ & $-6,0$ \\
\hline Asturias & 0,08 & 29,98 & 16,99 & 47,05 & 5,67 & 37,11 & 57,41 & 100,19 & 53,14 & 112,9 \\
\hline Canarias & 1,34 & & & 1,34 & 3,05 & & & 3,05 & 1,71 & 127,6 \\
\hline Cantabria & 4,14 & 20,80 & 29,63 & 54,57 & 16,39 & 58,05 & 93,53 & 167,97 & 113,4 & 207,8 \\
\hline $\begin{array}{l}\text { Castilla-La } \\
\text { Mancha }\end{array}$ & 11,2 & 79,61 & 30,22 & 121,03 & 11,48 & 195,51 & 109,80 & 316,79 & 195,76 & 161,7 \\
\hline $\begin{array}{l}\text { Castilla y } \\
\text { León }\end{array}$ & 35,91 & 196,06 & 137,77 & 369,74 & 91,54 & 304,98 & 196,01 & 592,53 & 222,79 & 60,3 \\
\hline Cataluña & 41,95 & 217,05 & 250,92 & 509,92 & 88,41 & 364,45 & 304,51 & 757,37 & 247,45 & 48,5 \\
\hline $\begin{array}{l}\text { Comunidad } \\
\text { Valenciana }\end{array}$ & 4,45 & 13,39 & & 17,84 & 3,74 & 14,07 & & 17,81 & $-0,03$ & $-0,2$ \\
\hline Extremadura & 0,56 & 5,06 & 14,47 & 20,09 & 4,37 & 17,91 & 15,70 & 37,98 & 17,89 & 89,0 \\
\hline Galicia & 23,01 & 112,63 & 141,1 & 276,74 & 37,61 & 350,48 & 543,26 & 931,35 & 654,61 & 236,5 \\
\hline La Rioja & 3,06 & 37,95 & 26,24 & 67,25 & 4,31 & 59,37 & 30,92 & 94,6 & 27,35 & 40,7 \\
\hline Madrid & 3,46 & 13,99 & 20,12 & 37,57 & 2,63 & 19,66 & 19,73 & 42,02 & 4,45 & 11,8 \\
\hline Murcia & 4,16 & 48,46 & & 52,62 & 14,60 & 55,39 & & 69,99 & 17,37 & 33,0 \\
\hline Navarra & 23,75 & 94,56 & 93,50 & 211,81 & 21,02 & 162,96 & 158,14 & 342,12 & 130,31 & 61,5 \\
\hline País Vasco & 10,59 & 25,18 & 5,51 & 41,28 & 34,79 & 88,88 & & 123,67 & 82,39 & 199,6 \\
\hline Total & 195,74 & 1.044 & $1.190,81$ & $2.430,55$ & 373,58 & $2.008,67$ & $1.798,1$ & $4.180,35$ & $1.749,8$ & 72,0 \\
\hline
\end{tabular}

Fuente: Comisión Nacional de Energía.

Lo primero que reflejan los cuadros anteriores es la evolución tan positiva que ha vivido el sector de la minihidráulica en España, debido a condiciones económicas favorables, que hasta su desaparición, ha generado el régimen especial de la producción eléctrica en España. Del total de instalaciones hidroeléctricas que se pueden acoger al mismo, las centrales minihidráulicas suponen el 60,9\% en 1998 y el $71,8 \%$ en 2013 , en cuanto a potencia acumulan el $62,1 \%$ en 1998 y el $58,7 \%$ en 2013 , y su producción de electricidad supone el $67,4 \%$ en 1998 y el 59,3\% en 2013.

En el conjunto de España, entre 1998 y 2013 se ha incrementado en un 90,7\% el número de centrales minihidráulicas, aunque con situaciones muy contrastadas entre las regiones (Cuadro No 13), la potencia ha aumentado un 52,7\% (Cuadro No 14) y la producción de electricidad ha subido un $72 \%$ (Cuadro No 15). En la actualidad, la mayor parte de la potencia instalada se localiza en la mitad septentrional de España (Figura $N^{\circ} 1$ ), en regiones donde se dan dos factores que influyen directamente en la instalación de centrales hidroeléctricas: las características del terreno por el 
que discurren los ríos y el régimen de éstos, que dependen a su vez de las particularidades geológicas y topográficas del relieve, y de las climáticas. En estas regiones la topografía es favorable para la producción de electricidad, pues abundan los grandes desniveles (Cabo, 1960). Galicia cuenta con abundantes precipitaciones por su clima atlántico y con un relieve montañoso favorable para la implantación de esta tecnología eléctrica. Y lo mismo sucede con las regiones que tienen en su territorio la Cordillera Pirenaica: Navarra, Aragón y Cataluña. En el caso de Castilla y León las condiciones topográficas de alta montaña y su potencial hidroeléctrico viene dado tanto desde la Cordillera Cantábrica como desde el Sistema Central.

El crecimiento reciente de la energía minihidráulica en este reducido número de regiones tiene sus antecedentes en el resurgimiento de los años ochenta, tras la entrada en vigor de la Ley sobre Conservación de la Energía. En Galicia, tanto por la incidencia de esta Ley como por otras iniciativas de la Xunta de Galicia, se despertó el interés por poner en servicio antiguos pequeños aprovechamientos hidroeléctricos que habían caído en desuso o en el olvido. El interés de las Administraciones central y autonómica, así como de particulares y grandes empresas como Fenosa, se plasmó en la rehabilitación de algunas de esas pequeñas centrales (De Torres et al., 1988). En Navarra, la normativa de fomento de las energías renovables llevó al acondicionamiento de muchas centrales antiguas, de pequeño caudal y con salto importante, situadas en las cabeceras de los ríos (Galán, 2004). En los años ochenta, el Gobierno de Navarra, junto con otras empresas, fundó Energía Hidroeléctrica de Navarra (EHN), con la intención de realizar un aprovechamiento racional y eficiente de las centrales que desde los años cincuenta se habían considerado marginales (Garrués, 1997). Entre 1991 y 1997 se pusieron en funcionamiento 12 minicentrales que suman una potencia de 39,76 MW. Tras la adquisición previa de parte del capital de EHN, en enero de 2005, Acciona se hace con la totalidad del capital de esa sociedad navarra, dentro de su política de diversificación de actividades e interés por las energías renovables. En Castilla y León, en 1992, hay 60 MW de potencia instalada en minicentrales hidroeléctricas y están solicitadas 125 nuevas instalaciones, con una potencia total de 263 MW (Avellaneda y Lavandeira, 1992). Según el Plan de Energías Renovables de Castilla y León, en el año 2000 se tendrían 157 MW instalados, lo que supondría más del 40\% del potencial instalable, estimado en 369 MW (Domínguez, 1996). Actualmente la potencia instalada en esta Comunidad Autónoma supera los 205 MW. Un caso reseñable también es el de la Comunidad de Madrid, donde la empresa regional de abastecimiento de agua, el Canal de Isabel II, construye tres minicentrales durante el primer quinquenio de los años noventa en sus embalses localizados al norte: Pinilla en 1992 (2.480 kW), El Atazar en 1993 (9.560 kW) y Torrelaguna en 1994 (4.700 kW).

Al finalizar 1997, hay en España más de 100 empresas relacionadas con el sector de la producción de la energía minihidráulica, que abarcan desde las ingenierías y empresas de equipamientos hasta las empresas constructoras, de explotación y mantenimiento, con amplios conocimientos y especialización. Esta gran experiencia en el sector es fruto de muchísimos años de actividad que han provocado la maduración y consolidación del mismo. A finales del siglo XX, la tecnología minihidráulica en España ha evolucionado favorablemente, alcanzándose una alta calidad y autosuficiencia. En esos momentos se tiende hacia la automatización integral de las minicentrales, mejorándose los rendimientos y reduciéndose los gastos de explotación y mantenimiento. Igualmente se busca implantar equipos normalizados que abaraten los costes de implantación (Instituto para la Diversificación y Ahorro de la Energía, 1998). 
Figura No 1

Potencia instalada en energía minihidráulica en las Comunidades Autónomas españolas, 1998 y 2013

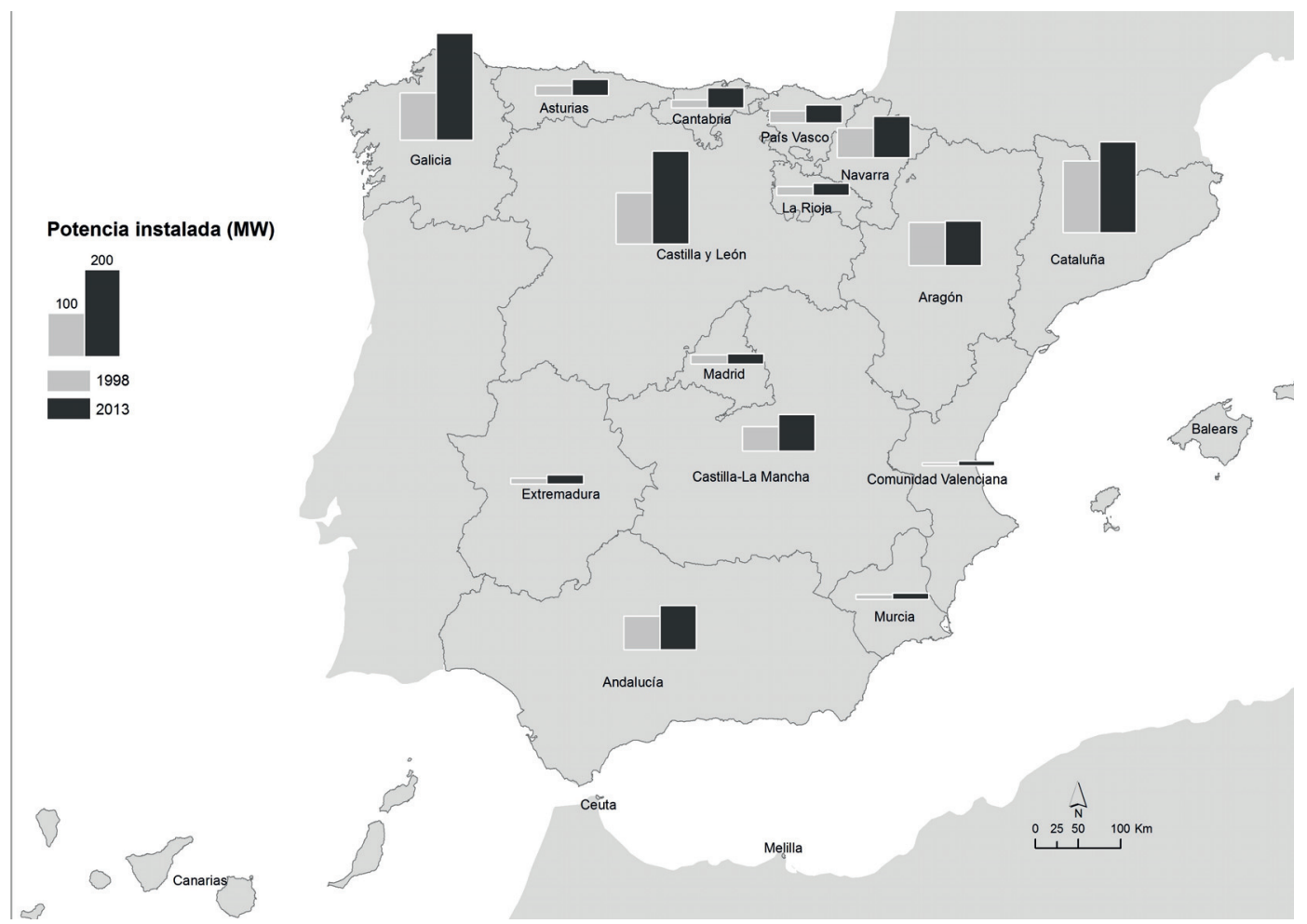

Fuente: Elaboración propia basado en datos de Comisión Nacional de Energía.

\section{Las dificultades recientes para su desarrollo}

Varios motivos explican las dificultades del presente y los problemas para el futuro de la tecnología renovable más limpia de producción eléctrica, la que menor impacto ambiental genera; entre ellos el reciente marco legal-económico que no solo desanima a la inversión en el sector, sino que ha llevado al cierre de minicentrales.

\section{Barreras tradicionales}

Los documentos de los Planes de Energías Renovables especifican las barreras (obstáculos) para el desarrollo de esta energía en nuestro país. El Plan 2011-2020 las clasifica en relación con el recurso hidráulico y con lo administrativo-medioambiental (Instituto para la Diversificación y Ahorro de la Energía, 2011). Salvo la referente a la disponibilidad de agua, que depende de la naturaleza, el resto de barreras las provocan todas las Administraciones, que son las encargadas de la planificación y de la gestión del territorio. Entre las barreras referentes a los recursos hidráulicos están:

- Falta de conocimiento en detalle del potencial del recurso hidráulico por emplazamientos, que dificulta o ralentiza la realización de proyectos. Quedan todavía muchos emplazamien- 
tos con infraestructuras existentes o en zonas de mínima afección ambiental, que pueden ser susceptibles de aprovechar hidroeléctricamente, de forma compatible con otros usos y desarrollables con criterios de sostenibilidad.

- Disminución de los recursos hídricos, por efecto del cambio climático, que afectará a la producción hidroeléctrica. Esta futura disminución de las aportaciones hidrológicas perturbará sobre todo a las centrales hidroeléctricas de tipo fluyente, sin capacidad de regulación, traduciéndose en una disminución de horas equivalentes de funcionamiento.

Y en lo referente a las barreras administrativas, destacan:

- Largas demoras para la obtención de las concesiones necesarias para el uso del agua, debido, entre otros motivos, a la dificultad para obtener la autorización ambiental previa necesaria. Para el otorgamiento de la concesión de aguas para uso hidroeléctrico es condición necesaria que el proyecto haya obtenido la Declaración de Impacto Ambiental favorable por parte del organismo competente. Fundamentalmente, dentro del proceso de tramitación concesional, largo y complicado, la mayor dificultad se encuentra en este paso, ya que se vienen produciendo demoras de casi 2 años, lo que hace que el proceso global pueda llegar a durar hasta 10 años, desanimando a los inversores potenciales que preferirán otros proyectos más atrayentes. También son comunes las dificultades en lograr conexiones a la red eléctrica asequibles.

- Oposición al otorgamiento de nuevas concesiones de agua de tipo fluyente por parte de determinados Organismos de cuencas hidrográficas. Actualmente, la interpretación de la Directiva Marco del Agua (DMA) está provocando sensibilidades contrarias a la explotación de aprovechamientos hidroeléctricos existentes y al futuro desarrollo de los mismos. El objetivo de esta Directiva es establecer un marco para la protección de las aguas continentales, costeras y subterráneas, mejorando el estado de los ecosistemas acuáticos y terrestres. En este sentido, la implantación de la DMA puede impedir el desarrollo del potencial fluyente disponible en cauces de ríos y la eliminación de minicentrales en desuso. Por otro lado, el establecimiento de los caudales de mantenimiento que se fijen en los instrumentos de planificación hidrológica puede afectar, en mayor o menor medida, a nuevos proyectos y a centrales en funcionamiento si los valores fijados son muy altos.

- Dificultades para la renovación del período de concesión de aguas en las centrales hidroeléctricas existentes. La no renovación de las concesiones puede derivar en abandono y sub-inversión de las plantas existentes durante los últimos años de explotación de las mismas.

\section{Problemas recientes}

Para juristas de prestigio, como José Antonio Martín Pallín, el sector está inmerso en una "cascada legislativa que ahoga las energías renovables. Basta una simple lectura del Boletín Oficial del Estado para comprobar una realidad que refleja una indeseable proliferación de normas legislativas. Se trata de un desbarajuste que ha sido denunciado en otras instancias internacionales y que ha dado lugar a una infinidad de reclamaciones ante tribunales nacionales a instancias de otros países" (Martín y Sánchez, 2014). Ante esta situación, muchas empresas de energías renovables 
recurren a la vía judicial después de que el Ministerio de Energía, Industria y Turismo haya desoído sus alegaciones, alterando, a través de la reforma energética, el marco retributivo que determinó el modelo financiero y de negocio en base al cual se realizaron las inversiones en los proyectos de energías renovables y cogeneración, con un claro perjuicio para quienes invirtieron en estas tecnologías. Esta situación ha sumido a muchas empresas del sector y a pequeños inversores particulares en una situación crítica, poniéndoles al borde de la ruina y abocándoles al cierre. Además, como vienen anunciando las asociaciones de renovables, la reforma mina la confianza en la seguridad jurídica de la economía española y está provocando la huída de inversiones internacionales. "Actualmente, los que estamos inmersos en el mundo de las energías renovables estamos dedicando más tiempo y recursos a cómo salvar los muebles negociando financiación con los bancos, interponiendo recursos, disminuyendo costes, etc. que en crear nuevas oportunidades con el riesgo de que un día nos machaquen. Es triste, pero es asi", resume uno de los empresarios del sector de las energías renovables (Mosquera, 2014).

Como ejemplo, el martes 9 de septiembre de 2014 se publicaron 21 nuevos recursos contencioso-administrativos contra el R.D. 413/2014 y la Orden IET/1045/2014. Entre quienes interponen recursos contra ambas normativas dominan las empresas dedicadas a las tecnologías renovables, pero también hay empresas de cogeneración. Entre las minihidráulicas está el caso de "Minicentral San Miguel, SLU”"5.

En julio de 2015, la Asociación de Productores de Energía Hidroeléctrica (Urwatt), que representa a la cuarta parte de las minicentrales hidroeléctricas existentes, anuncia que denunciará en Bruselas la penalización a que las somete el Ministerio de Industria. La puntilla al sector se consuma con una Orden publicada en el BOE (IET/1344/2015, de 2 de julio) por la que se aprueban los parámetros retributivos. Para Urwatt, "Los efectos de este cambio son absolutamente devastadores para las centrales hidroeléctricas de potencia instalada menores de $1 \mathrm{MW}$. Simplemente se acaba de firmar, con este cambio, el cierre de la mayor parte de las instalaciones", declara al medio de difusión La Celosía ${ }^{6}$ Jorge García-Egocheaga, que representa los intereses de Urwatt en Bruselas. Según los cálculos realizados desde la Asociación, una central con potencia instalada menor de $1 \mathrm{MW}$, en el anterior régimen económico, bajo el R.D. 661/2007, facturaba 84.485,42€, tomando como ejemplo una central con potencia instalada de $380 \mathrm{~kW}$ (que es la potencia media de las centrales menores de $1 \mathrm{MW}$ ). Con la nueva regulación, teniendo en cuenta que el precio medio estipulado es de $42 €$ por MW, pasa a facturar $42.242,17 €$. A este importe hay que restarle el 7\% correspondiente al Impuesto sobre el Valor de la Producción de Energía Eléctrica, y el 2,2\% correspondiente a la tasa del Canon Hidroeléctrico. La facturación neta estimada queda en tan sólo $38.355,89 €$, menos de la mitad de lo que se ingresaba antes de la normativa publicada en el BOE. "Con este importe no es posible explotar y amortizar una instalación de estas características. Ni tan siquiera cubrir los costes operativos (personal, mantenimiento predictivo, preventivo, correctivo, técnico legal, representante, costes de desvíos, peajes de acceso, seguros, cánones autonómicos, IAE, IBI, costes administrativos, etc.). Y por supuesto es del todo imposible cubrir la amortización", explica García-Egocheaga.

"La minihidráulica se ahoga", Energías Renovables, 20 de febrero de 2014. Disponible en Internet: http://www.energias-renovables.com/articu lo/la-minihidraulica-se-ahoga-20140220

6 La Celosía, 22 de julio de 2015. Disponible en Internet: http://www.lacelosia.com/la-penalizacion-que-somete-industria-las-mini-centrales-hidroelectricas-sera-denunciada-juncker/ 
"La mayor parte de las instalaciones hidráulicas con potencia inferior a $1 \mathrm{MW}$ tienen sus actas de puesta en marcha entre el año 1989 y 1991. Por tanto, según se les vaya acabando las primas (con esta nueva Orden ya ha sucedido para las minicentrales de 1989 y anteriores) no podrán afrontar sus costes operativos y de mantenimiento, por lo que en cuanto se produzca la primera avería las instalaciones irán cerrando. La quiebra de todas estas instalaciones va a producir la total destrucción del tejido empresarial, empleo rural, sostenibilidad de patrimonio industrial histórico, etc. $Y$ todo ello lo sufre un sector que no ha sido nunca el causante del déficit tarifario ni ha participado en el incremento de costes del sistema eléctrico. En el año 2000 todas estas instalaciones ya existían y no había déficit de tarifa", subraya el representante de Urwatt en Bruselas.

La prensa nacional y regional también ha dado buena cuenta de los recursos planteados por el sector de las renovables ante la nueva normativa y de las resoluciones judiciales. Sirven como ejemplo las siguientes noticias:

- "350 recursos contra el recorte de las energías renovables en España". Diario El Mundo, 8 de octubre de 2014.

- "El Constitucional respalda el recorte de las primas a las renovables. Los productores afectados mantienen el caso abierto ante el Tribunal de Justicia Europeo". Diario El País, 13 de enero de 2016.

- "España gana la primera batalla internacional por las renovables. El arbitraje internacional desestima la demanda de dos fondos internacionales por el recorte de primas del Gobierno de 2010". Diario El País, 25 de enero de 2016.

- "El Supremo avala el recorte de 1.700 millones de Rajoy a las renovables. El Tribunal considera que la nueva regulación es constitucional y se ajusta al derecho comunitario". Diario El País, 1 de julio de 2016.

Las últimas decisiones del Gobierno en materia de energía renovable han quedado recientemente respaldadas por el Tribunal Supremo. En nota de prensa de 2 de junio de 2016, el Consejo General del Poder Judicial publica esta noticia: "El tribunal Supremo avala el Real Decreto y la Orden Ministerial que regulan las instalaciones de energía renovable y los parámetros retributivos". La Sala emite tres sentencias que resuelven recursos contra el Real Decreto 413/1045/2014, de 6 de junio, y contra la Orden IET/1045/2014, de 16 de junio, por la que se aprobaron los parámetros retributivos de las instalaciones de energía renovable 7 . Todas estas medidas de contención ponen en entredicho el cumplimiento del Plan de Energías Renovables 2011-2010, en lo referente a las tecnologías de producción eléctrica en centrales minihidráulicas.

\section{Conclusiones}

La energía hidráulica ha sido una fuente de producción eléctrica desde finales del siglo XIX en aquellos lugares en los que una corriente de agua y un salto permitían construir una minicentral hidroeléctrica. Con la invención de la corriente alterna se construyen redes eléctricas que permiten llevar la electricidad a grandes distancias. Para poder satisfacer las nuevas demandas de elec-

http://www.poderjudicial.es/cgpj/es/Poder-Judicial/Sala-de-Prensa/Notas-de-prensa/El-Tribunal-Supremo-avala-el-Real-Decreto-y-la-Orden-ministerial-que-regulan-las-instalaciones-de-energia-renovable-y-los-parametros-retributivos 
tricidad que necesitaba España, a partir de los años cincuenta del pasado siglo se construyeron grandes centrales hidroeléctricas y térmicas, lo que provocó que las minicentrales hidroeléctricas acabaran cerrando en su mayoría, ante la imposibilidad de poder competir con esas instalaciones.

Las crisis del petróleo de los años setenta llevan a un nuevo planteamiento energético, en el que se considera la necesidad de aprovechar las energías renovables por su carácter autóctono, carácter que permite reducir considerablemente las importaciones de energía, además de su demostrado menor impacto ambiental. UNESA, en 1980, realiza un estudio donde manifiesta el gran potencial hidroeléctrico que tiene España pendiente de aprovechar.

La Ley sobre Conservación de Energía, promulgada en 1980, es la primera medida política que lleva al resurgimiento de la energía minihidráulica, porque se establecen unas condiciones económicas favorables para los productores. En 1997 se aprueba la Ley del Sector Eléctrico y se consolida el régimen especial de la producción eléctrica, que comprende la producción en instalaciones de energía eléctrica a partir de energías renovables, cogeneración y residuos. Esta Ley ha sido fundamental en el desarrollo de las energías renovables en España, y dentro de ellas de la minihidráulica. La Ley del Sector Eléctrico de 2013 establece un nuevo régimen jurídico y económico para las instalaciones de producción de energía eléctrica incluidas en el régimen especial. Se abandona el modelo basado en la producción eléctrica establecido desde la Ley de 1997. Desaparece el régimen especial y pasan todas las instalaciones a regirse por la misma normativa y asumir las obligaciones del mercado. Tras la aprobación de cada Ley, una abundante normativa ha ido marcando el régimen económico y de funcionamiento, y por tanto la evolución del sector de la minihidráulica.

También, desde los años ochenta se han aprobado varios planes energéticos, con carácter general y específicos para las energías renovables. La energía minihidráulica siempre ha quedado por debajo de las previsiones de crecimiento, debido a las dificultades y obstáculos que esta tecnología ha padecido.

Los conflictos que generan los usos del agua en España, las autorizaciones que se necesitan para construir una minicentral, y el nuevo régimen económico de la producción de electricidad en este tipo de centrales son, entre otros, factores que explican sobradamente la situación actual de estancamiento y retroceso del sector, y la probabilidad de que esta regresión se alargue en el tiempo.

\section{Referencias bibliográficas}

AGENCIA ESTATAL DE EVALUACIÓN DE LAS POLÍTICAS PÚBLICAS Y LA CALIDAD DE LOS SERVICIOS. Evaluación del Plan Español de Energías Renovables 2005-2010. Madrid: Ministerio de Política Territorial y Administración Pública, 2011.

ARROYO, F. El sistema eléctrico del Júcar y la electricidad madrileña. En: Simposio Internacional Globalización, innovación y construcción de redes técnicas urbanas en América y Europa, 18901930 Brazilian Traction, Barcelona Traction y otros conglomerados financieros y técnicos, Universidad de Barcelona, Facultad de Geografía e Historia, Barcelona, 23-26 de enero 2012, p. 1-23 
AVELLANER, J. y LAVANDEIRA, J.C. Las energías renovables en Castilla y León. Valladolid: Consejería de Economía y Hacienda de la Junta de Castilla y León, 1992.

CABO, A. Factores geográficos de la industria eléctrica española. Geographica, 1960, año VII, p. 28-58.

CASTRO, A. Minicentrales hidroeléctricas. Madrid: Instituto para la Diversificación y Ahorro de la Energía, 2006.

CASTRO-GIL AMIGO, J.; CARNICER DÍEZ, C.; DE LA QUADRA SALCEDO, T.; BAÑO LEÓN, J.M.; IDEL GUAYO CASTIELLA, I.; DOMINGO LÓPEZ, E.; LEIVA LÓPEZ, A.; CHRISTIAN PIELOW, J.; LÓPEZ-RODRÍGUEZ, A.M. y NAVARRO RODRÍGUEZ, P. Riesgo regulatorio en las energías renovables. Cizur Menor: Thomson Reuters-Aranzadi, 2014.

DE TORRES, M.P.; PAZO, A.J. y SANTOS, J.M. Los embalses de Fenosa y la Geografía de Galicia en el centenario de Don Pedro Barrié de la Maza 1888-1988. La Coruña: Fundación Pedro Barrié de la Maza, 1988.

DOMÍNGUEZ, U. Implicación de entes locales en la explotación recursos endógenos: minicentrales hidroeléctricas en la comarca de Béjar. En: III Congreso de Economía Regional de Castilla y León. Consejería de Economía y Hacienda de la Junta de Castilla y León, Segovia, 1992, p. 238-252

DOMÍNGUEZ, U. Minicentrales y medio ambiente. En: DOMÍNGUEZ, U. (Coordinador). Energías renovables y medio ambiente. Valladolid: Universidad de Valladolid, 1994a, p. 319-337.

DOMÍNGUEZ, U. Minicentrales hidroeléctricas en la Sierra de Gredos: condicionantes y viabilidad económica. En: IV Congreso de Economía Regional de Castilla y León, Consejería de Economía y Hacienda de la Junta de Castilla y León, Burgos, 1994b, p. 387-401.

DOMíNGUEZ, U. Recursos minihidráulicos en Castilla y León. Consideraciones medioambientales y repercusiones socioeconómicas. En: $V$ Congreso de Economía Regional de Castilla y León. Consejería de Economía y Hacienda de la Junta de Castilla y León, Ávila, 1996, p. 1.495-1.508.

DOMíNGUEZ, U. Electricidad verde en Castilla y León: el camino hacia un sistema energético sostenible. En: VII Congreso de Economía Regional de Castilla y León, Consejería de Economía y Hacienda de la Junta de Castilla y León, Soria, 2000, p. 1682-1697.

EUROBSERVER. The state of renewable energies in Europe. Edition 2016. Paris: 16 th EurObserv'Er Report, 2017.

ESPEJO, C. La energía eléctrica en régimen especial en España. En: Amica Verba in honorem Prof. Antonio Roldán Pérez, Universidad de Murcia, Murcia, 2005, p. 249-263.

ESPEJO, C. y GARCÍA, R. Agua y energía: producción hidroeléctrica en España. Investigaciones Geográficas, 2010, No 51, p. 107-129.

ESPEJO, C. y GARCÍA, R. La energía eólica en la producción de electricidad en España. Revista de Geografía Norte Grande, 2010, № 51, p. 115-136. 
EUROPEAN SMALL HYDROPOWER ASSOCIATION. Guía para el desarrollo de una pequeña central hidroeléctrica. Bruselas, 2006.

FROLOVA, M. Landscapes, water Polycy and the ecolution of discourse on hydropower in Spain. Landscape Research, 2010, Vol. 35, N² 2, p. 235-257.

FROLOVA, M.; ESPEJO, C.; BARAJA, E. y PRADOS, M.J. Paisajes emergentes de las energías renovables en España. Boletín de la Asociación de Geógrafos Españoles, 2014, № 66, p. 223-252.

FROLOVA, M.; JIMÉNEZ, Y.; SÁNCHEZ, M.A.; REQUENA, A. \& PÉREZ, B. The evolution of renewable landscapes in Sierra Nevada (Southern Spain). In: FROLOVA, M.; PRADOS, M.J. \& NADAÏ, A. (Editors). Renewable Energies and European Landscapes. Lesson from Southerm European Cases. Berlín: Springer Science and Business Media, 2015, p. 43-61.

GALÁN, F.J. Minihidráulica en Navarra. Revista de Obras Públicas, 2004, № 3.446, p. 23-36.

GALÁN, F.J. Minihidráulica. En: AYESA, P. y SÁNCHEZ, F. (Coordinadores). Las energías renovables en España. Diagnóstico y perspectivas. Barcelona: Fundación Gas Natural, 2006, p. 307-336.

GARRUÉS, J. Empresas y empresarios en Navarra. La industria eléctrica, 1888-1986. Pamplona: Departamento de Educación y Cultura del Gobierno de Navarra, 1997.

INIESTA, J. y GARCÍA, P.A. Minihidráulica. El recorrido de la energía. Madrid: Dirección General de Industria, Energía y Minas del Gobierno de la Comunidad de Madrid, 2002.

INSTITUTO PARA LA DIVERSIFICACIÓN Y AHORRO DE LA ENERGÍA. Las energías renovables en España. Balances y perspectivas. Madrid: Ministerio de Ciencia y Tecnología, 1998.

INSTITUTO PARA LA DIVERSIFICACIÓN Y AHORRO DE LA ENERGÍA. Plan de Fomento de la Energías Renovables en España. Madrid: Ministerio de Ciencia y Tecnología, 1999.

INSTITUTO PARA LA DIVERSIFICACIÓN Y AHORRO DE LA ENERGÍA. Impactos ambientales de la producción energética. Análisis del ciclo de vida de ocho tecnologías de generación eléctrica. Madrid, 2000.

INSTITUTO PARA LA DIVERSIFICACIÓN Y AHORRO DE LA ENERGÍA. Plan de Energías Renovables en España 2005-2010. Madrid: Ministerio de Industria, Comercio y Turismo, 2005.

INSTITUTO PARA LA DIVERSIFICACIÓN Y AHORRO DE LA ENERGÍA. Plan de Energías Renovables 2011-2020. Madrid: Ministerio de Industria, Comercio y Turismo, 2011.

IZQUIERDO, I. y DOMÍNGUEZ, U. El Plan Energético Nacional, 1991-2000. En: DOMíNGUEZ, U. (Coordinador). Energías renovables y medio ambiente. Valladolid: Universidad de Valladolid, 1994, p. 405-437.

LÓPEZ, A.; OGAYAR, B.; GÓMEZ, P.; MEDIAN, M.A. y LA CAL, J.A. El potencial minihidráulico de Sierra Mágina. Sumután, 2006, № 23, p. 109-125. 
MARTÍN, A. y COLINO, A. (Directores). Diccionario Español de la Energía. Aranjuez: Ediciones Doce Calles, 2003.

MARTÍN, J.A. y SÁNCHEZ, J. La cascada legislativa que ahoga las energías renovables. En Riesgo regulatorio en las energías renovables. Cizur Menor: Thomson Reuters-Aranzadi, 2014, p. 219-241.

MARTÍNEZ, I. La minihidráulica en España. En: SÁNCHEZ, J. (Coordinadora). Energías renovables. Madrid: Centro de Investigaciones Energéticas, Mediambientales y Tecnológicas, 1995, p. 21-42.

MOSQUERA, P. “El BOE publica 21 recursos contra la reforma energética del Gobierno", Energías Renovables, 9 de septiembre de 2014. Disponible en:

http://www.energias-renovables.com/articulo/el-boe-publica-21-recursos-contra-la-20140909

PENCHE, C. La pequeña hidráulica. En: MARTíN, A. y COLINO, A. (Directores). Diccionario Español de la Energía. Aranjuez: Ediciones Doce Calles, 2003, p. 86.

PÉREZ, F.J. Proyecto de aprovechamiento hidroeléctrico del embalse del Torcón. Madrid: Escuela Técnica Superior de Ingenieros de Caminos, Canales y Puertos. Universidad Politécnica de Madrid, 2002.

PRADOS, M.J.; BARAJA, E.; FROLOVA, M. y ESPEJO, C. Integración paisajística y territorial de las energías renovables. Ciudad y Territorio. Estudios Territoriales, 2012, № 171, p. 127-143.

ROJAS, S. Energía minihidráulica: propuestas sobre aprovechamientos potenciales. En: Energías renovables. Cáceres: Universidad de Extremadura, 2001, p. 115-138.

SÁNCHEZ, J. Minicentrales hidroeléctricas. En: DOMÍNGUEZ, U. (Coordinador). Energías renovables y medio ambiente. Valladolid: Universidad de Valladolid, 1994, p. 287-317.

SANTOS, F. Minicentrales hidráulicas. En: DE JUANA, J.M. (Coordinador). Energías renovables para el desarrollo. Madrid: Editorial Paraninfo, 2003, p. 261-308.

SOTO, M. O impacto ecolóxico das minicentrais na Galiza. Adega Cadernos, 1996, № 1, p. 7-28.

UNESA. ¿Qué es una minicentral hidroeléctrica? En: La electricidad en España. Madrid: UNESA, 2003, p. 77-78.

UNITED NATIONS INDUSTRIAL DEVELOPMENT ORGANIZATION (UNIDO) e INTERNATIONAL CENTER ON SMALL HYDRO POWER (ICSHP). World Small Hydropower Development Report. Viena y Hangzhou, 2016.

URTEAGA, L. El proceso de electrificación en Cataluña (1881-2000). En: TARRAGÓ, S. (Editor). Obras Públicas en Cataluña. Presente, pasado y futuro. Barcelona: Real Academia de Ingeniería, 2003, p. 355-376. 
